\title{
An experimental study on sediment transport and bed evolution under different swash zone morphological conditions
}

\author{
José M. Alsina \\ Dipartimento di Ingegneria Civile, Edile e Architettura (DICEA), Università Politecnica delle \\ Marche, 60131 Ancona, Italy.j.alsina@univpm.it \\ Iván Cáceres \\ Laboratori d'Enginyeria Marítima, Universitat Politècnica de Catalunya, \\ 08034 Barcelona, Spain. i.caceres@upc.edu \\ Maurizio Brocchini \\ Dipartimento di Ingegneria Civile, Edile e Architettura (DICEA), Università Politecnica delle \\ Marche, 60131 Ancona, Italy. m.brocchini@univpm.it \\ Tom E. Baldock \\ School of Civil Engineering, University of Queensland, Brisbane, Qld 4072, Australia. \\ t.baldock@uq.edu.au
}

\begin{abstract}
In this study, new large scale experimental data are presented showing evidences of a link between the swash zone dynamics and the surf zone morphodynamics. Two sets of large scale experiments are presented. The first set of experiments investigates the swash and surf dynamics under the same hydrodynamic forcing but with two different swash zone morphological conditions, one of which was created by manual reshaping of the sub-aerial beach-face. It is shown that more dissipative swash zone conditions (a more mildly sloping beach-face) significantly reduce the rate of seaward
\end{abstract}


sandbar migration such that it almost ceases during the performed experimentation time. This behavior is compared to a second set of experiments which show the natural sand bar offshore migration under almost identical hydrodynamic forcing. The changes in the sandbar migration are investigated in terms of the differences in the swash zone dynamics. The more reflective swash zone is characterized by more intense backwashes that, in turn, promote significant quantities of sediment suspension during the interaction of the backwash with the subsequent bore. The dissipative swash zone leads to a larger number of wave-swash interactions, reducing the backwash magnitudes and the magnitude of suspended sediment concentration events in the swash zone, with a corresponding reduction in the offshore suspended sediment transport. The total offshore sediment transport rates are also shown to reduce, leading to the observed modification of the sandbar migration.

Keywords: swash zone, bar migration, sediment transport, suspended sediment concentration, large scale experiments, wave-swash interactions.

\section{1.- Introduction}

The swash zone is that part of the beach alternatively covered and exposed by wave uprush and backwash. It is a region where the final dissipation of short-waves (sea and swell) takes place while the low-frequency energy (typical wave periods of around 10 to $30 \mathrm{~s}$ ) is generally reflected back to sea. In addition, interactions between incoming waves and preceding swash events can lead to the generation and reflection of further low-frequency waves (Watson et al., 1994).

During the last ten years important progress has been done in the understanding of the swash dynamics that are reflected in several review papers (Brocchini and Baldock, 2008; Elfrink and 
Baldock, 2002; Masselink and Puleo, 2006). However, there are still many uncertainties to be solved with respect to the swash zone, specially, when dealing with sediment dynamics. In particular, the 1st International Workshop on Swash Processes, held in Lisbon 2004, stated, among the main points on swash zone research, two aspects relevant to the present work which are: i) the need for advances in the knowledge of sediment transport in the swash zone and ii) that the swash zone must be viewed as an integral part of the surf zone and dune region and the effect of these areas on the swash zone and vice-versa is not well understood and need for an important research effort (Puleo and Butt, 2006).

Typically, the swash motion is characterized in relation to the hydrodynamic forcing at the seaward boundary (incident wave condition) and the beach face morphological conditions. Two types of swash dynamics are hence identified: on dissipative beaches, with gentle beach slopes and low Iribarren numbers, the swash flows are dominated by standing, low-frequency motions, while on reflective beaches, characterized by steep beach slopes and large Iribarren numbers, the swash flows are dominated by incident high-frequency bores.

Several authors have shown that on dissipative beaches, shoreward sediment transport induced by infragravity, highly turbulent uprushes is balanced by long infragravity backwashes. The bed level evolution is, therefore, the resultant of the small difference between the two components (Butt and Russell, 1999; Masselink et al., 2005). Masselink and Russell (2006) and Miles et al. (2006) performed comparison of velocity and suspended sediment transport data obtained on a relatively flat dissipative and on a steeper intermediate beach. These studies showed a similar beach evolution with accretion in the upper mid swash area but erosion in the lower swash zone. On the steeper intermediate beach, sediment transport is dominated by the incident wave frequency while infragravity frequencies dominated the oscillatory component of sediment transport in the dissipative swash. Higher variance of velocity and suspended sediment concentration were observed 
in the intermediate beach with larger number of uprushes and backwashes acting, and resulting in higher mean suspended sediment concentration.

Most of the available sediment transport data on the inner surf and swash zones rely on direct measurements from sediment traps (Alsina et al., 2009; Baldock et al., 2005; Jackson et al., 2004; Masselink and Hughes, 1998; Masselink et al., 2009) or co-located measures of suspended sediment concentration and velocity (Aagaard and Hughes, 2006; Alsina and Cáceres, 2011; Masselink et al., 2005; Puleo et al., 2000). Total load traps studies have evidenced a reasonable correlation of measured sediment mass and swash velocities and larger coefficients of proportionality during the uprush than during the backwash, hence, denoting higher transport efficiency during the uprush based on velocity transport concepts (Masselink and Hughes, 1998; Masselink et al., 2009). On the other hand, sediment trap studies focusing on the uprush have shown the importance of sediment entrainment during bore collapse at the seaward limit of the swash zone and the subsequent advection up the beach by wave uprush (Alsina et al., 2009; Jackson et al., 2004). The representativeness of the trapped sediment load of the total sediment transport responsible of the beach-face evolution has been questioned by Masselink et al. (2009), showing sediment transport derived from bed evolution at a swash time scale being, generally, several times larger than those derived from the traps.

Co-located measurements of suspended sediment concentration and velocity, in the other hand, imply that the bed load transport, occurring very close to the bed level, is not considered. Very recent studies have obtained indirect measurements of sediment transport in the swash zone by accurate bed level change measurements during the emerged periods between swash events (Blenkinsopp et al., 2011; Houser and Barrett, 2010). These studies show that the net sediment fluxes over individual swash events are of the same order of the uprush and backwash loads, i.e. not a small difference between two large numbers, and that relatively few swash events can be 
responsible for the majority of the net morphological change (Blenkinsopp et al., 2011).

The dynamics of the swash zone are not only important because of their local effect and influence (e.g. wave inundation, overtopping and overwash, beach face evolution, dune erosion and beach recovery) but also because the dynamics can directly affect processes occurring in the surf zone as a whole (Brocchini and Baldock, 2008; Elfrink and Baldock, 2002). For example, dune erosion is a predominant swash zone process and the sediment mobilized from the dune may feed sandbars, modifying the surf zone morphodynamics. Conversely, onshore bar migration and welding to the beach-face occurs during accretive conditions, where the swash and surf zone processes are both important in controlling the morphodynamics (Aagaard et al., 2006). A method to account for how the swash zone influences the whole surf zone dynamics in numerical models was introduced by Brocchini and Peregrine (1996), who defined flow boundary conditions at the shoreline that were suitable to be implemented in wave-averaged hydrodynamic models. Brocchini (2006) reviewed this concept and illustrated the use of integral swash models to formulate shoreline boundary conditions (SBC). Recently, hydrodynamic numerical models have been proposed that include swash zone hydrodynamics with different degrees of complexity (Roelvink et al., 2009; Van Dongeren and Svendsen, 1997). In particular, Roelvink et al. (2009) proposed a morphodynamic numerical model including swash processes in the hydrodynamics by means of the Generalized Lagrangian Mean (GLM) formulation (Andrews and Mc Intyre, 1978) and several swash zone processes in the sediment transport sub-modules, e.g. sediment avalanching on a dune face. However, while these models are focused on improving model performance by including specific processes happening in the swash region, the influence of swash conditions over the overall beach morphodynamic has not been properly accounted for, or specifically investigated, as yet.

This paper considers this issue and investigates the influence of the swash zone dynamics on the sediment exchange with the surf zone. Two controlled large-scale experiments have been performed 
to measure bar migration with the same hydrodynamic forcing and morphology in the surf zone, but with different beach morphology within the swash zone in each experiment. The mechanisms leading to the swash zone influence on the temporal bar migration are also analyzed.

This paper is organized as follows. A description of the experimental setup and the analysis techniques are given in section 2. The results are presented in section 3 , and discussed in terms of the resulting morphodynamics and the different swash zone processes between the two experiments. Finally, the main conclusions are discussed and summarized in sections 4 and 5.

\section{2.- Experimental description}

\section{1.- Experimental facility}

The data presented here were obtained in the Canal de Investigacion y Experimentacion Maritima (CIEM) at the Universidad Politecnica de Cataluna (UPC), Barcelona. It is a large-scale wave flume of $100 \mathrm{~m}$ long, $3 \mathrm{~m}$ width and $4.5 \mathrm{~m}$ depth. Most of the present analysis is based on a set of experiments corresponding to the data collected during the SCESE project (Suspended Concentration Events in Swash Experiments). Moderately energetic random waves were generated $\left(H_{s}=0.46 \mathrm{~m}\right.$ and $\left.T_{p}=4.4 \mathrm{~s}\right)$, repeating the same wave realization for a series of 12 tests (the same wave time series is repeated 12 times). Each test comprised 500 waves, with a total duration of around 31 minutes (around 6 hours of total experimentation time). A second set of experiments is used for comparison, the data collected comes from the Hydralab III SANDS project (Scaling and Analysis and New instrumentation for Dynamic bed testS). Similar wave conditions were generated, repeating the same wave realization for a series of 47 tests. Each test comprised 500 waves, with a total duration of around 27 minutes (around 21 hours of total experimentation time). A summary of the wave generation parameters is given in table 1 . The random wave time series 
correspond to a Jonswap spectrum $(\gamma=3.3)$.

Table 1. Measured wave conditions during experiments

\begin{tabular}{|c|c|c|c|c|}
\hline Experiment & Hs (m) & Tp (s) & $\begin{array}{l}\text { Water } \\
\text { depth (m) }\end{array}$ & $\begin{array}{l}\text { Iribarren } \\
\text { num }(\xi)\end{array}$ \\
\hline SANDS & 0.53 & 4.14 & 2.47 & 0.47 \\
\hline SCESE & 0.48 & 4.4 & 2.50 & 0.53 \\
\hline
\end{tabular}

\section{2.- Morphology}

The initial experimental set up (figure 1) corresponds, at the final beach area, to a constant sloping beach with a gradient of $1 / 15$ and the same sand was used in both experiments. The beach was made of commercial well-sorted sand with a medium sediment size, such that $d_{50}=0.25 \mathrm{~mm}, d_{10}=$ $0.154 \mathrm{~mm}$ and $d_{90}=0.372 \mathrm{~mm}$. The water depth at the wave maker was of $2.50 \mathrm{~m}$ for the SCESE experiments and $2.47 \mathrm{~m}$ during SANDS. The cross-shore coordinate $(x)$ has its origin at the initial still-water shoreline, to facilitate the comparison among experiments, and is positive shoreward. The vertical coordinate $(z)$ for bed level measurements has the origin at the still-water level and is negative downward. The beach evolution along the center-line of the wave flume was measured with a mechanical wheeled bed profiler that measures both the sub-aerial and submerged beach elevation; more details can be found in Baldock et al. (2011). The overall vertical profile accuracy is estimated to be $\pm 10 \mathrm{~mm}$. The vertical datum for the profile data is the SWL.

During the SCESE experiments, a bar was generated during test 1 and migrated seaward until the end of test 8 . After completion of test 8 ( 4.13 hours of experimentation time), the emerged beach face above the SWL was manually reshaped to obtain more dissipative conditions within and only within the swash zone. Figure 2 shows a detailed view of the profile before and after manual reshaping. The tests, then, continued with identical incident wave conditions for a further four runs 
to investigate the effect of the new morphological swash conditions on the sediment transport and evolution of the existing offshore sandbar. Comparison of inner surf and swash zones behavior before and after beach-face reshaping is performed. Eventually a qualitative comparison of the short term bar behavior with the known bar dynamics after 47 tests obtained from a set of data obtained under SANDS experiments will be done. Beach profiles were measured after tests 1, 2, 4, 6, 8 (before and after manual reshaping), 9, 10 and 12 corresponding to experimentation time $T_{\exp }=$ $0.52,1.03,2.07,3.1,4.13,4.65,5.17$ and 6.20 hours.

\section{3.- Instrumentation}

Water surface elevations along the flume and in the surf zone were obtained from resistive wave gauges distributed along the wave flume at cross-shore locations $x=-68.17,-67.19,-66.20,-65.20$, $-58.48,-55.31,-33.48,-23.61 \mathrm{~m}$. Detailed flow and sediment concentration measurement in the inner surf and swash areas were made both before and after manual reshaping. The water surface elevation in the inner surf and swash zones was measured by means of two types of Acoustic Displacement Sensors (ADS), the first ones were Ultralab® (General Acoustic) ULS-40D with a measuring range between 0.18 and $3.5 \mathrm{~m}$ and a nominal accuracy of $1 \mathrm{~mm}$ placed at the surf zone due to its wide range. The second ones were Microsonic $(\operatorname{mic}+130)$ with an application range between $0.2-1.7 \mathrm{~m}$ and a nominal accuracy of $0.2 \mathrm{~mm}$; these were used at the swash region to measure the water surface elevation during the swash event and the bed level position during emerged time periods (Turner et al., 2008). Pore pressure transducers (PPT) (STS, ATM/N) were also used to measure the water surface elevation in the inner surf zone, and some of these were collocated with an ADS to check the measured elevations with different sensors. The flow velocity was measured by a series of Acoustic Doppler Velocimeters (ADV) from Nortek (Vectrino model), while the suspended sediment concentration was measured using Optical Backscatter Sensors (OBS) supplied by D\&A Instrument Company (OBS 3+). The cross-shore position and vertical elevation relative to the bed (when relevant) of the different instruments are given in Table 2 and 
illustrated in figure 1. The ADV, OBS and ADS were collocated in the cross-shore, and in order to obtain a high spatial resolution during the experiments and to avoid scour and flow disturbance, the ADVs were located close to one of the flume walls, while the OBSs were located at the same crossshore location and vertical elevation with respect to the bed level but close to the opposite wall. To ensure consistency in measurement at different tests, the vertical elevations with respect to the sandy bed were checked at the beginning of each test, with collocated instruments adjusted accordingly to the same initial elevation at the commencement of each test.

Table 2. Equipment distribution along the surf and swash zone during the SCESE experiments, the values in brackets and gray indicate vertical elevations from the bottom; more than one value means that different acquisition devices were deployed at the same cross-shore location but at different vertical elevations.

\begin{tabular}{ll}
\hline Sensor & x cross-shore position in $\mathrm{m}($ elevation above the bed level in $\mathrm{m})$ \\
\hline ADV & $-7.41(0.2,0.15),-5.6(0.11,0.11),-2.69(0.04,0.04)$ and $-0.41(0.04,0.04)$ \\
OBS & $-7.41(0.03,0.07),-2.69(0.03,0.07),-0.41(0.03,0.07), 0.58(0.03)$ and $1.92(0.03)$ \\
PPT & $-7.32,-5.53,-0.49,-0.41,-0.33$ and -0.25 \\
ADS & $-25.25,-11.17,-8.17,-2.76,-1.64,-0.54,0.45,1.82,3.46,4.3$ and 5.32 \\
\hline
\end{tabular}

ADV velocity data were processed and spike noise eliminated using the method developed by Goring and Nikora (2002). Low-quality data, where either the signal to noise ratio was below 15 or the signal amplitude was below 75 counts, were discarded and cubic interpolation was performed. Each OBS was calibrated using the CIEM sand samples and the glycerol technique developed by Butt et al. (2002).

\section{3.- Results}

\section{1.- Bar dynamics}

Computed Iribarren numbers ranged between 0.4 and 0.5 during the eight initial tests for both data sets. Wave breaking was visually identified as predominantly plunging (Alsina and Cáceres, 2011). 
The cross-shore distribution of significant wave height and the beach profile during the different tests in the SANDS experiment are illustrated in figure 3. The significant wave height was computed from the water surface elevation power spectrum. During test 1 wave breaking occurred at around $x=-12 \mathrm{~m}$, and a small bar started to be generated around the breaker location, with the crest located at $x=-10.73 \mathrm{~m}$, figure $3 \mathrm{~b}$. Here, the bar crest location is defined as the location of the maximum bar elevation with respect to the initial planar bed. As the experiment proceeded, the bar moved offshore, as did the breakpoint, and by the end of test $9\left(T_{\exp }=4.05 \mathrm{~h}\right)$ the bar crest was located at $x=-14.25 \mathrm{~m}$ with a bar crest elevation above the initial beach profile of $0.33 \mathrm{~m}$. For subsequent tests the bar location continued to migrate seaward, increasing in volume at the same time. The wave breaking location similarly migrated seaward with the bar crest location. This behavior is consistent with many previous experimental studies and with the behavior of bars on single-barred natural beaches. After the final test (test $47, T_{\exp }=21.15 \mathrm{~h}$ ), the bar crest was located at $-16.61 \mathrm{~m}$ with a bar crest elevation above the initial beach profile of $0.55 \mathrm{~m}$. During the tests, the inner surf zone and lower and mid- swash zone, sub areas classification according to Aagaard and Hughes (2006), eroded significantly, with a shoreline retreat of $1.6 \mathrm{~m}$ and $3.41 \mathrm{~m}$ after tests 9 and 47, respectively. The upper part of the swash zone, on the other hand, experienced a slight accretion with a berm development of around $0.12 \mathrm{~m}$ over the initial profile.

Similar to figure 3, figure 4 illustrates the significant wave height distribution and beach profile pertaining to the SCESE experiments. From test 1 to test 8 , the significant wave height and beach profile behavior is similar to that of the previous SANDS experiments. A bar generated close to the initial breaking location and the bar and the breaking locations migrated seaward during the running of subsequent tests. After test $8\left(T_{\exp }=4.13 \mathrm{~h}\right)$ the bar crest was located at $\mathrm{x}=-12.47 \mathrm{~m}$ with a crest elevation above the initial profile of $0.39 \mathrm{~m}$. The inner surf and low and mid swash zones also showed similar amounts of erosion, with a shoreline retreat of $1.37 \mathrm{~m}$, while the upper swash zone experienced a small accretion of around $0.02 \mathrm{~m}$. 
After test 8, the sub-aerial beach profile above the SWL was manually reshaped to obtain a more dissipative lower swash zone, as illustrated in figure 2. No change to the profile was made offshore of the SWL. Following this change in the swash zone morphology, the bar migration rate reduced very significantly during the subsequent tests (9-12) and ceased almost completely. Simultaneously, the morphological response in the swash region changed, becoming relatively stable in the lower swash zone, with only minor erosion, but with a change to moderate accretion in the upper swash zone.

There were slight differences in hydrodynamic forcing and water depth between SANDS and SCESE experiments and therefore small differences in bar location and crest elevation in time exist between them. During SANDS experiments the offshore sandbar migration over a experimentation time of around $21 \mathrm{~h}$ were measured and this behavior represents the erosive overall trend expected for SCESE before and after reshaping.

Cross-shore sediment transport rates $(Q)$ were computed from the measured beach profiles using the balance between bed-level changes and sediment transport gradients, also called the Exner equation:

$$
Q\left(x_{i}\right)=Q\left(x_{i-1}\right)-p \int_{x_{i-1}}^{x_{i}} \frac{\Delta z}{\Delta t} d x
$$

where $Q\left(x_{i}\right)$ is the integral volume of sediment transport $\left(\mathrm{m}^{2} / \mathrm{s}\right)$ at position $x_{i}, \Delta z$ is the difference in bed elevation $(\mathrm{m})$ between measured profiles, $\Delta t$ is the time difference $(\mathrm{s})$ between measured profiles and $p$ is the solid fraction, approximately 0.6 for the laboratory sand. A known boundary condition needs to be set $(Q(x)=0)$ at either the landward or seaward end of the beach. We used a 
condition of no transport landward of the run-up limit. A correction is introduced in the calculated $Q(x)$ to obtain zero sediment fluxes across the boundaries (Baldock et al., 2011), which distributes measurement errors evenly across the profile. Figure 5 shows the computed sediment fluxes for the SCESE experimental data before and after manual reshaping of the swash morphology. Before reshaping, the sediment fluxes show strong offshore transport in the surf zone, with a negative peak close to the wave breaking location and landward of the bar crest. Strong offshore transport also occurs in the inner surf and lower swash zone. The mid and upper swash areas ( $\mathrm{x} \sim 3$ to $8 \mathrm{~m}$ ) experienced positive (shoreward) sediment fluxes, consistent with the berm formation noted above. This combination of shoreward transport in the upper swash zone in conjunction with offshore transport in the lower swash region, i.e. a steepening of the upper beach face during moderately erosive conditions in the absence of dune or scarp erosion, is a common feature of both laboratory experiments (Holmes et al., 1996) and natural beaches (Weir et al., 2006) over both long time-scales and individual swash events (Brocchini and Baldock, 2008). After beach-face reshaping, and under the same hydrodynamic forcing, very significant changes in the sediment flux occur in the surf and swash zones as a result of the new beach-face conditions. Close to the bar location, the offshore transport reduces by a factor of 4 , consistently with the observed reduction of the rate of bar migration. Further, the transport direction is reversed in the lower and mid swash areas, with accretion occurring, in contrast to the erosive behavior that occurred prior to reshaping. The point of inversion between shoreward sediment transport in the upper swash and seaward transport in the lower swash region moves seaward after reshaping by about $2 \mathrm{~m}$, into the lower swash zone and inner surf zone. Also, the location of the maximum rate of onshore transport in the upper swash zone is translated from $\mathrm{x} \sim 5 \mathrm{~m}$ before reshaping to $\mathrm{x} \sim 2 \mathrm{~m}$ after reshaping, and the magnitude of the shoreward transport increases. Overall, conditions become significantly less erosive, as expected and as intended by reshaping the swash zone. 


\section{2.- Hydrodynamics and sediment dynamics}

As shown above, more dissipative swash conditions promote significant changes in the sediment transport pattern in the surf zone and reduce and almost stop the seaward migration of the breakpoint bar. In this section a detailed analysis of the processes behind this change is presented.

The water surface elevation power spectrum for test 8 (before reshaping) and 10 (after reshaping), is shown, in figure 6a for two different cross-shore location $\mathrm{x}=-66.2 \mathrm{~m}$ (close to the wave paddle) and $\mathrm{x}=-0.46 \mathrm{~m}$ (close to the shoreline). Close to the wave paddle the computed power spectrum shows a similar pattern before and after reshaping with most of the energy concentrated at the incident frequency. Closer to the shoreline $(\mathrm{x}=-0.46 \mathrm{~m})$, strong dissipation of the energy within the incident frequency component is observed due to wave breaking. At this location $(x=-0.46 \mathrm{~m})$, energy transfer to sub-harmonics is also observed, with three significant low-frequency peaks appearing at around $0.024,0.043$ and $0.065 \mathrm{~Hz}$. It is also noticeable that the peak at $0.065 \mathrm{~Hz}$ has a lower energy content for test 10 than for test 8 . Alsina and Cáceres (2011) showed that the $0.065 \mathrm{~Hz}$ component is attributed to standing long waves being reflected at the shoreline for the SANDS data. Therefore, a more dissipative beach-face condition would result in less reflection at the shoreline and smaller energy at this frequency as displayed in figure 6a. The energy associated with the selected low frequency band $(0.065 \mathrm{~Hz})$ has been computed according to,

$$
E(f)=\int_{f_{1}}^{f_{2}} S(f) d f
$$

where $f_{1}$ and $f_{2}$ are the band width limits around the selected frequency, to be 0.06 and $0.07 \mathrm{~Hz}$ respectively and $S(f)$ is the spectral density of the water surface elevation. The distribution of the computed energy by test numbers and at different cross-shore locations are illustrated in figure $6 \mathrm{~b}$ 
where an important energy reduction at the selected frequency is observed after manual reshaping (after test 8) but only at locations shoreward of $x=-1 \mathrm{~m}$. The energy associated at this frequency band and these locations remain smaller for successive tests after reshaping while at locations seaward of $x=-1 \mathrm{~m}$ the beach reshaping does not induce any significant change in the spectral energy. The energy associated with the incident frequency bands or with low frequencies different than the $0.065 \mathrm{~Hz}$ band has been also computed using eq. (2) and showed no significant variability with respect to test number (figures not shown). Therefore the new swash zone morphology resulting from the reshaping promotes changes in the long wave reflection that are noticeable locally in the inner surf zone (shoreward of $x=-1 \mathrm{~m}$ ) but does not affect significantly the long wave or incident wave energy close to the bar location. The local effect of the reshaping on the hydrodynamics is further demonstrated by computing reflection coefficients using selected wave gauges close to the wave paddle. Reflection coefficients have been computed using the least squares methodology developed by Mansard and Funke (1980) and showed similar values before and after reshaping.

The Acoustic Displacement Sensors (ADS) when deployed in the swash area were used to track the bed level position between successive swash events, i.e. when the bed is exposed. Here a technique similar to that used by Turner et al. (2008) was employed to obtain the bed level elevation variations. Dry events in the swash zone were identified when the acoustic signal showed signal variation of less than $0.002 \mathrm{~m}$, repeated over a time spans larger or equal than $2 \mathrm{~s}$. There are some uncertainties about this methodology, especially when the ADSs are deployed in the field (Baldock, 2009); in particular the practical accuracy of sensors is of about $1 \mathrm{~mm}$ (although specified by the manufacturer to $0.018 \mathrm{~mm}$ in optimal conditions), foam can obscure the bed, long-shore gradients in sediment transport exist and the bed is often not exposed in the lower swash region for several successive swash events. Also, a slowly draining thin film of water (and sediment slurry) frequently remains on the beach face below the seepage face after the shoreline retreats, which appears as a 
slow decline in the apparent bed level and makes determining real bed level changes (order 1-2 $\mathrm{mm}$ ) under moderate swash events difficult. Under controlled laboratory conditions many of these problems are overcome (fresh water with very little foam, no long-shore transport and quicker drainage of the beach face). Nevertheless, the present study focuses on the overall trends in the bed evolution (major bed level variations larger than $3 \mathrm{~mm}$ ) and no attention is paid to smaller variations in the apparent bed level.

Time series of the bed level changes computed from the data using the criterion outlined above are presented for test 8 on figure 7 and for test 10 on figure 8 . The cross-shore locations where the bed level changes were computed are indicated in the figures, and correspond to locations in the upper swash area, $x=3.46,4.3$ and $5.32 \mathrm{~m}$. For test 8, cycles of erosion and accretion are observed, induced by single or series of swash events, but the overall behavior is of erosion of around $0.01 \mathrm{~m}$ at locations $x=3.46$ and $4.3 \mathrm{~m}$. This behavior is observed on natural beaches, where such interswash measurements show that long periods of accretion are often interrupted by short periods of erosion, and vice versa (Brocchini and Baldock, 2008). During the interval shown, much of the observed erosion is promoted by a few highly energetic swash groups occurring between times 1600 and $1800 \mathrm{~s}$. One of the most significant erosion events occurs at the time interval 1720 to 1740 s. Such an erosive event occurs here during the swash event characterized by the maximum run-up excursion. Other significant erosive swash events occur at times of 1620-1640, 1769 and $1780 \mathrm{~s}$. The bed level changes are found to be highly repeatable in terms of their time of occurrence during successive tests from 1 to 8 , especially in relation to the erosive event arising from the swash event with the largest run-up. Caceres and Alsina (2011) have analyzed such bed level changes in detail and show them to be consistent with the measurements from the mechanical bed profiler, which show erosion up to the cross-shore location $x=5-5.2 \mathrm{~m}$ and accretion further shoreward. Referring to figure 5 , the inflexion point appearing at around $x=5 \mathrm{~m}$ in the computed sediment transport rate shows that this is the location of inversion between erosion and accretion. 
After reshaping, and during test 10, the time variation of bed level changes shows a behavior very different from the behavior observed before reshaping. While cycles of accretion and erosion remain evident at cross-shore locations $x=3.46$ and $4.3 \mathrm{~m}$, the overall trend of erosion ceased at $x=$ $3.46 \mathrm{~m}$, while overall accretion occurred at $x=4.3 \mathrm{~m}$, in contrast with the trend at the end of test 8 as shown above. The rate of accretion in the upper swash region also increases markedly between test 8 and test 10. Again, while the cycles of erosive and accretive bed level changes still occur for test 10 , the large erosive bed level changes are significantly smaller than those during test 8 , by a factor of two. The behavior shown in figure 8 for test 10 is consistent with the bed level changes observed during tests 9,11 and 12 (not shown for clarity) and with the computed sediment fluxes displayed in figure 5. These show a significant change in the location of the maximum onshore transport rate from $x \sim 5 \mathrm{~m}$, for tests $2-4$, to $x \sim 2 \mathrm{~m}$ for tests 9 and 10, i.e., the inner surf and lower swash zone change from an erosive state to an accretive state.

Detailed time-histories of the water surface elevation at different cross-shore positions within the inner surf and swash zone and the shoreline elevation and cross-shore position are illustrated in figure 9 for test 8 , before reshaping, (figure 9a) and test 10, after reshaping (figure 9b). Water surface and shoreline elevation values are shown on the left axis while cross-shore shoreline position is shown on the right axis, as well as the approximate sensor location. The time window shown is between $1600-1770 \mathrm{~s}$, which is characterized by significant erosive events and the largest run-up. The shoreline elevation is depicted with a solid black line, and was computed using the water surface elevations from the ADS, with the time-dependent bed level variations removed. The shoreline position was obtained using a cubic interpolation to estimate the intersection of the water surface and beach face. Standard video-image techniques were discarded because of the lack of foam under these experimental conditions made it difficult to identify the shoreline with sufficient resolution for automated tracking. 
Before reshaping (figure 9a), well defined long swash events, highly correlated to the incident wave groups, are observed, where the swash oscillations are dominated by the incident bore group structure on the relatively steep beach face (Baldock and Holmes, 1999). The swash zone is delimited by the envelope of minimum run-down which oscillates between $x=-2$ and $-1 \mathrm{~m}$. The outer swash region, defined as the zone where wave-swash interactions occur, is bordered by $x=-2$ $\mathrm{m}$ and $x=3 \mathrm{~m}$. Shoreward of this location $(\mathrm{x}=3 \mathrm{~m})$, the swash signal is dominated by pure swash motion (i.e., free from interactions with subsequent waves) in the form of pure run-up or backwash. Strong interaction events, of the "strong wave-backwash interactions" type (Caceres and Alsina, 2011; Hughes and Moseley, 2007), are also evident at times (e.g. 1606, 1625, 1669, 1683, 1693, 1730 s). Such events are promoted by a large backwash which encounters the next arriving bore. These events imply important momentum exchange, resulting in a quasi stationary hydraulic jump also known as "backwash bore" (Hibberd and Peregrine, 1979).

After reshaping, the swash dynamics over the more dissipative beach face shows a significantly different picture (figure 9b). The seaward limit of the swash zone, delimited by the envelope of rundown, is more dynamic and oscillates over a greater beach width than for test 8 , between $x=-2$ and $1 \mathrm{~m}$. The outer swash area, where wave-swash interactions occur, is also broader, oscillating between $x=-2 \mathrm{~m}$ and $x=4 \mathrm{~m}$. The shoreline oscillation is less controlled by the wave-group structure than in test 8 , and much more significantly influenced by individual incident bores, which continuously interact with preceding swashes. More interactions of the "wave-overrun" type, i.e., an incident wave overtaking the preceding run-up (Hughes and Moseley, 2007), are evident for test 10 (refer, for example, to the time span from 1700 to $1730 \mathrm{~s}$ in figure $9 \mathrm{~b}$ compared to figure $9 \mathrm{a}$, and the sensors located at $x \sim 0$ and $2 \mathrm{~m}$ (dark and light blue respectively). More frequent "weak wavebackwash interaction" occurs in test 10, rather than the very frequent "strong wave-backwash interaction" that occurs in test 8. Swash events (sequences of multiple bores) are longer and more 
coherent during test 8 , resulting in strong low frequency backwash events driven by the wave-group structure. Longer backwashes allows for stronger seaward acceleration to occur and higher backwash velocities (see figure 10a), thus enabling greater momentum exchange in the wavebackwash interaction region.

This different hydrodynamic behavior before and after reshaping has a significant influence on the sediment dynamics. Time series of horizontal velocity at one location in the inner surf zone $(x=-$ $0.38 \mathrm{~m}$ ) and Suspended Sediment Concentrations (SSC) at different locations within the inner surf and swash zone $(x=-0.38,0.61,1.9 \mathrm{~m})$ are illustrated in figure 10 . Horizontal velocities for test 8 and 10 are shown in figure $10 \mathrm{a}$, while SSC for test 8 and 10 are depicted in figures $10 \mathrm{~b}$ and $\mathrm{c}$, respectively. Before beach-face reshaping, a series of large erosive events leads to high sediment volume loss on the beach face during the time interval $t=1600-1800 \mathrm{~s}$ (refer to figure 7 for bed level changes). These erosive events are associated with energetic swash events, characterized by the largest run-up events. The measured sediment concentration shows concentration peaks during these energetic events, coincident with strong wave-backwash interaction during large backwashes (see for example, on figure $10 \mathrm{~b}$, the concentrations at $x=0.61 \mathrm{~m}$ at times $t=1625$, and $1722 \mathrm{~s}$ and the concentrations at $x=1.9 \mathrm{~m}$ at times $t=1669$ and $1693 \mathrm{~s}$ among others). These strong sediment suspension events are repeated at the same time during each of tests 4 to 8 before the reshaping is performed.

After beach reshaping, on the other hand, the number of SSC peaks associated with "wavebackwash interactions" is reduced significantly. (See figure 10c compared to figure 10b). Other significant SSC events illustrated on figure 10c are associated with incident bores without backwash interactions, in which the bore-associated flow velocity is positive. See, for example, figure 10c at times $t=1610$ and $1742 \mathrm{~s}$. These are characterized by similar SSC events occurring successively in time at sensors placed at different cross-shore locations. Such SSC events are induced by the same 
incident bore promoting sediment suspension at different locations and from sediment being advected with the bore propagation from one sensor location to the next (Alsina et al., 2009), which is associated with beach accretion (Pritchard and Hogg, 2005).

The influence of the new shoreline configuration on the changes in SSC is, again, highly repeatable for different tests. The observed patterns during the more "reflective" beach-face conditions, illustrated in figure $10 \mathrm{~b}$ for test 8 , are similarly observed for tests 4, 5, 6 and 7 (i.e., SSC events of similar magnitude occurring at the same time interval). The SSC events during the more "dissipative" beach-face conditions, illustrated for test 10 on figure 10c, are similarly repeated during tests 9, 11 and 12. This means that the hydrodynamics, SSC and calculated suspended sediment transport rates can be directly compared at the same location for different tests.

This is illustrated in figure 11, where water surface elevation, horizontal velocity, SSC and sediment transport are shown before and after reshaping together with ensemble averaged values. The ensemble averaging was performed using data measured in tests 5, 6 and 8 before reshaping (data of test 7 showed malfunctioning of ADV signal and were discarded), and for tests 10, 11 and 12 after reshaping. Suspended sediment transport is computed from each OBS sensor as the product between the flow velocity and the suspended sediment concentration from the co-located OBS and ADVs, multiplied by the OBS vertical spacing, which assumes a uniform sediment concentration over that portion of the water column. Figure 11 illustrates measured and computed ensemble averaged values corresponding to sensors placed at $x=-0.38 \mathrm{~m}$. This location is shoreward of the mean shoreline, and the period of time where major erosion is observed, $1600 \mathrm{~s} \leq t \leq 1800 \mathrm{~s}$, is displayed.

Test repeatability is evaluated by means of a Coefficient of variation (Cv) estimated separately before and after reshaping as the standard deviation of the measured values at different test but 
same time instant, made dimensionless with the ensemble value at that instant. $\mathrm{Cv}$ is averaged over the time series and expressed in $\%$ as a measured of intra-test variability. The coefficient of variation is found to be similar before and after reshaping with mean values of $19 \%$ for water surface elevation, $29 \%$ for horizontal velocity, $50 \%$ for SSC and $24 \%$ for computed suspended sediment transport at the location $\mathrm{x}=-0.38 \mathrm{~m}$. These values are considered to be of reduced intensity, taking in account turbulence, the episodic nature of suspension events and the bottom evolution between test and, therefore, the tests are considered to be highly repeatable. Furthermore, it is concluded that measured sediment transport at different tests are comparable and correctly represented by ensemble averaged despite of bottom evolution or possible differences in instrument elevation.

Comparing, on figure 11, ensemble averaged values before and after reshaping, shows that relatively little variation occurs in the water surface elevation, the differences being within the intertest variability. The measured velocity shows larger variations, and particularly negative velocities are larger before reshaping (see, for example, velocities at times $t=1624,1666,1709,1725,1731$, 1756 and 1768 s). This is consistent with the reduction in the magnitude of the largest backwashes observed after reshaping, figure $9 \mathrm{a}$ with respect to $9 \mathrm{~b}$, which results from a larger number of waveswash interactions. The net result is larger negative (offshore) sediment transport before reshaping, induced by the coincidence of high SSC with high negative velocities from the stronger backwashes. The integral suspended sediment transport for the whole time series at this location is twice larger (more negative, i.e. offshore) than before reshaping the profile. This, in turn, results in less sediment being transported from the swash to the surf zone after the reshaping and the consequent influence on the sandbar migration. The differences in ensemble averaged suspended transport at this location before and after reshaping represents a $179 \%$ variation with respect to mean values and is, therefore, considered to be a direct consequence of beach face reshaping and cannot be attributed to inter-test variability. 
An $\mathrm{r}$ analysis similar to that of figure 11 has been done for cross-shore locations $x=-2.66 \mathrm{~m}$ and $7.38 \mathrm{~m}$, in the surf zone (not displayed). Similarly, these locations show little variability in water surface elevation and horizontal velocity with relatively small inter-test coefficient of variations, which ensures test repeatability and representativeness of test-ensemble averaging. However, at these locations a higher variability in SSC and suspended sediment transport was observed. Moreover, at the same cross-shore locations a reduction was found in suspended sediment transport, which is there much smaller than at $\mathrm{x}=-0.38 \mathrm{~m}$; however such a reduction is of the same order of the inter-test variability and cannot be considered as significant.

\section{4.- Discussion}

The present experimental work shows that modifying the swash zone beach-face gradient, and hence the swash conditions, promotes variations in the swash zone dynamics that also affect the inner surf zone morphodynamics. The modification in the swash conditions also affects the offshore breaker sandbar behavior, as evidenced by a reduction of the short-term sandbar migration. This behavior has been previously reported for smaller scale tests in Baldock et al. (2007) and Brocchini and Baldock (2008), in which the change to more dissipative swash zone conditions induced onshore migration of a previously stable offshore breaker bar. In Baldock et al. (2007), a relatively larger change was made to the beach-face morphology than in the present work and the bar was initially stable, rather than migrating offshore, which explains the difference with the results presented here.

We have shown how the new swash conditions significantly modify the cross-shore distribution of the sediment transport rates (see figure 5). This suggests a reduction in the short-term rate of offshore migration of the bar. The measured bar migration speed, based on the bar crest position, 
was about $-0.62 \mathrm{~m} / \mathrm{h}$ on average before manual reshaping (test $7-8$ ), which reduced to $-0.38 \mathrm{~m} / \mathrm{h}$ in the test just after manual reshaping and the migration rates become equal to zero $\mathrm{m} / \mathrm{h}$ after test 9 to the end of experimentation time (average migration rate after reshaping $=-0.12 \mathrm{~m} / \mathrm{h}$ ). This difference in comparison with a previous experiment, SANDS, evidences that such a distinct bar behavior is a direct consequence of the different swash zone conditions generated, and cannot be attributed to the beach approaching equilibrium. With the present data available, the swash zone link with longer bar migration periods cannot be further demonstrated due to the short duration of experiments and this issue will be analyzed in a future set of experiments.

The impact of changes in swash zone sediment transport and hydrodynamics on a larger region of the surf zone arises because the intensity of the sediment transport in the swash region is often an order of magnitude greater than in the surf zone and because the beach-face gradient has a controlling influence on the nearshore hydrodynamics. These experiments suggest that the swash hydrodynamics should be taken into due account in models for both offshore and onshore bar migration.

The more dissipative swash zone conditions induced by reshaping the beach face promote a larger amount of interaction between incident bores and the preceding swash events, as illustrated in figure 9a,b. The degree of wave-swash interaction depends on the ratio between the natural period of the swash events $T_{s}$ and the incident wave period $T$; for $T>T_{S}$ little or no interaction occurs, while strong wave-swash interactions are expected to occur as the parameter $\hat{T}=T_{S} / T$ increases. The artificial beach face reshaping toward a milder slope and a more dissipative swash condition would increase $T_{s}$, promoting a larger number of wave-swash interactions since the incident wave period is unchanged (Baldock and Holmes, 1999; Puleo and Holland, 2001). A further indication of the change in the degree of wave-swash interaction can be quantified using the natural period of the swash groups, $T_{s g}$, defined here as the mean time between successive zero-up and zero-down 
crossings of the time dependent shoreline location, where zero is the still water shoreline position. $T_{s g}$ has a mean value of $15.5 \mathrm{~s}$ for test 8 , smaller than the frequency of the incident wave groups during this experiment $(0.04 \mathrm{~Hz})$, and a mean value of $23.19 \mathrm{~s}$ during test 10 . Therefore, a larger number of wave-swash interactions occur after reshaping.

The increase in the degree of swash interaction after reshaping translates into a reduction in the backwash magnitude, which is reflected in a reduced magnitude of the maximum offshore velocities measured close to the minimum run-down location $(x=-0.38 \mathrm{~m})$. Also, a more variable mean rundown location is observed after reshaping, so the seaward limit of the swash zone oscillates over a larger region of the beach face, and therefore the influence of strong backwashes is less concentrated around the SWL.

Measured sediment concentrations show consistently higher mean values and a greater number of significant suspension events before reshaping of the beach face. Many of the measured SSC events observed before reshaping are associated with strong wave-backwash interactions in which a longwave backwash interacts with the next bore, leading to a quasi-stationary hydraulic jump ("backwash bore") and a large amount of sediment in suspension over the water column. The large sediment concentrations are attributed to the strong vorticity generated at the interaction and injected into the water column down to the bed level, inducing high sediment suspension (Hibberd and Peregrine, 1979; Matsunaga and Honji, 1980; Soldati and Marchioli, 2009) and the resuspension of sediment mobilized during the preceding backwash. The number of SSC events associated with strong wave-backwash interactions has been shown to decrease after the reshaping, as a result of the reduction in backwash magnitude on the more mildly sloping profile. The two different swash zone conditions show, therefore, different sediment suspension patterns. Strong backwash events have been measured at the scale of wave groups before reshaping, and these induce strong seaward-directed suspended sediment fluxes at the seaward swash boundary, and 
might also force strong seaward bed-load sediment fluxes. Bed-load sediment transport cannot be measured by state-of-art OBSs but such a sediment transport mode is expected to be important in the observed beach-face erosion ((Nielsen, 2009), page 123). After reshaping, backwash events were continuously interrupted by incoming bores which inhibited the offshore suspended sediment transport at the swash seaward boundary. This would reduce erosion in the lower swash region. Indeed, Van Wellen et al. (2000) developed a swash zone sediment transport model that included the influence of wave-swash interaction by truncating the backwash transport, and found that transport switched from offshore to onshore as the degree of swash interaction increased. This change occurred at $\hat{T}=T_{s} / T \approx 1.1$. However, the van Wellen (2001) model was for monochromatic waves. If it is assumed instead that the shoreline dynamics is dominated by the incident wave group structure and this period $\left(T_{g} \sim 24 \mathrm{~s}\right)$ is used, such that $\hat{T}_{\mathrm{g}}=T_{s g} / T_{g}$, then $\hat{T}_{\mathrm{g}}=0.65$ for test 8 (before reshaping) and $\hat{T}_{\mathrm{g}}=0.97$ for test 10 (after reshaping), consistent with the Van Wellen (2000) concept. These results are also consistent with the experiments presented in Baldock et al. (2011; 2010), which show that wave groups induce more erosion than monochromatic waves with equivalent energy, in part because of the larger backwashes and the reduced interaction between every wave run-up.

Therefore, the short-term variation in the bar migration induced by the modifications to the swash zone conditions is explained by the increase in wave-swash interactions which, inhibit the intensity and frequency of large backwashes, and associated suspended sediment and sediment transport from the swash to the surf zone. The data show that a more dissipative swash zone induces local changes (in the inner surf and swash) in the hydrodynamics and sediment transport that in turn promote the modifications in the short term bar behavior. The analyzed data show a clear evidences of a reduction in suspended sediment being transported from the swash to the surf zone $(\mathrm{x}=-0.38 \mathrm{~m})$ after beach reshaping and as a direct consequence of more dissipative swash zone conditions. This, 
in turn, inhibits the amount of sediment suspension in the inner surf zone which is available for transport seaward by the mean currents and long waves in the inner surf zone. This results in a reduction of seaward transport in the swash and inner surf zone, which leads to a reduction of sediment supply to the bar and the observed reduction of the bar migration rate. However, the data do not clarify the direct mechanism that links the reduction in the sediment supply in the inner surf zone to the bar morphodynamics.

While the swash zone influence on the surf zone morphodynamics has been clearly demonstrated, swash conditions are rarely considered in surf zone studies. Improvements in such models may result from considering the swash zone morphology and hydrodynamics. The present experiments show the effect of an artificially modified swash zone morphology on the sediment exchange from the swash to the surf zone. Although this modification represents an artificial experimental situation, similar changes are found in natural conditions. For example, swash zone conditions frequently change significantly on a seasonal basis on many beaches around the world (i.e., "winter" and "summer" beach-face profiles) and their impact on surf zone dynamics should be considered further. Also many natural tidal beaches exhibit a steeper upper section, and a flat low tide section. Measurements on such terraced beaches suggest that the dynamics of the terrace/steep beach exhibit characteristics of separate dissipative/reflective sites (Miles and Russell, 2004). Other important practical considerations arise, for example for beach nourishment projects. Usually beach nourishment implies the introduction of sand which is coarser than the original, which might potentially modify the mean beach-face gradient. Such modifications, as has been demonstrated here, might cause important changes in the swash dynamics that, in turn, affect the surf zone bar dynamics. 


\section{5.- Conclusions}

Novel experimental evidence of the influence of the swash zone on surf zone dynamics has been presented. A data set from controlled large-scale experiments clearly demonstrate that the artificial modification of the sub-aerial beachface to more dissipative swash conditions introduces significant changes in the swash zone dynamics, in turn leading to variations in the surf zone morphodynamics and a reduction in the short-term rate of offshore bar migration. These new results are consistent with previous small-scale experiments (Baldock et al., (2007) and Brocchini and Baldock (2008)) that showed an increase in the shoreward bar migration rate with a milder beach slope in the swash zone.

The modification to a more dissipative swash zone leads to a larger number of wave-swash interaction and a reduction in the magnitude and frequency of large backwashes. An associated reduction in high SSC events also occurs, leading to a significant reduction of offshore suspended sediment transport. This is clearly reflected in a reduction in the total offshore sediment flux across the surf zone and a tendency to greater onshore transport in the swash zone. Thus, the changes to the swash zone morphology significantly reduce the sediment availability and the potential sediment transport to the bar, which has implications for modeling surf zone morphology under both natural and artificial (beach nourishment) conditions.

\section{Acknowledgments}

We gratefully acknowledged the collaboration of CIEM staff. SANDS is a project funded by the EU-Hydralab III framework (contract number: 022441936 - RII3) while SCESE was possible without external funding and thanks to the contribution of the CIEM technicians with special mention to Quim Sospedra who allowed these experiments to be done. The first author is currently supported by the FP-7 Marie Curie postdoctoral grant PIEF-GA-2009-252374. 


\section{References}

Aagaard, T., Hughes, M., G., Møller-Sørensen, R. and Andersen, S., 2006. Hydrodynamics and sediment fluxes across an onshore migrating intertidal bar. Journal of Coastal Research, 22(2): 247-259.

Aagaard, T. and Hughes, M.G., 2006. Sediment suspension and turbulence in the swash zone of dissipative beaches. Marine Geology, 228(1-4): 117-135.

Alsina, J.M. and Cáceres, I., 2011. Sediment suspension events in the inner surf and swash zone. Measurements in large-scale and high-energy wave conditions. Coastal Engineering, 58(8): 657-670.

Alsina, J.M., Falchetti, S. and Baldock, T.E., 2009. Measurements and modelling of the advection of suspended sediment in the swash zone by solitary waves. Coastal Engineering, 56(5-6): 621-631.

Andrews, D.G. and Mc Intyre, M.E., 1978. An exact theory of nonlinear waves on a lagrangianmean flow. Journal of Fluid Mechanics, 89(4): 609-646.

Baldock, T.E., 2009. Discussion of "measurement of wave-by-wave bed-levels in the swash zone" by ian 1. Turner, paul e. Russell, tony butt [coastal eng. 55 (2008) 1237-1242]. Coastal Engineering, 56(3): 380-381.

Baldock, T.E. et al., 2011. Large-scale experiments on beach profile evolution and surf and swash zone sediment transport induced by long waves, wave groups and random waves. Coastal Engineering, 58(2): 214-227.

Baldock, T.E. and Holmes, P., 1999. Simulation and prediction of swash oscillations on a steep beach. Coastal Engineering, 36(3): 219-242.

Baldock, T.E., Hughes, M.G., Day, K. and Louys, J., 2005. Swash overtopping and sediment overwash on a truncated beach. Coastal Engineering, 52(7): 633-645.

Baldock, T.E., Manoonvoravong, P. and Pham, K.S., 2007. Beachface morphology and surf beat sediment transport in laboratory scale surf and swash zones. Journal of Coastal Research(SI 50, ICS'07): 631 - 635.

Baldock, T.E., Manoonvoravong, P. and Pham, K.S., 2010. Sediment transport and beach morphodynamics induced by free long waves, bound long waves and wave groups. Coastal Engineering, 57(10): 898-916.

Blenkinsopp, C.E., Turner, I.L., Masselink, G. and Russell, P.E., 2011. Swash zone sediment fluxes: Field observations. Coastal Engineering, 58(1): 28-44.

Brocchini, M., 2006. Integral swash-zone models. Continental Shelf Research, 26(5): 653-660.

Brocchini, M. and Baldock, T.E., 2008. Recent advances in modeling swash zone dynamics: Influence of surf-swash interaction on nearshore hydrodynamics and morphodynamics. Reviews of Geophysics, 46: RG3003.

Brocchini, M. and Peregrine, D.H., 1996. Integral flow properties of the swash zone averaging. Journal of Fluid Mechanics, 317: 241-273.

Butt, T., Miles, J., Ganderton, P. and Russell, P., 2002. A simple method for calibrating optical backscatter sensors in high concentrations of non-cohesive sediments. Marine Geology, 192(4): 419-424.

Butt, T. and Russell, P., 1999. Suspended sediment transport mechanisms in high-energy swash. Marine Geology, 161(2-4): 361-375.

Caceres, I. and Alsina, J.M., 2011. A detailed, event-by-event analysis of suspended sediment concentration in the swash zone. Continental Shelf Research (in press)..

Elfrink, B. and Baldock, T., 2002. Hydrodynamics and sediment transport in the swash zone: A review and perspectives. Coastal Engineering, 45(3-4): 149-167.

Goring, D.G. and Nikora, V.I., 2002. Despiking acoustic doppler velocimeter data. Journal of 
Hydraulic Engineering, 128(1): 117-126.

Hibberd, S. and Peregrine, D.H., 1979. Surf and run-up on a beach: A uniform bore. Journal of Fluid Mechanics, 95: 323-345.

Holmes, P., Baldock, T.E., Chan, R.T.C. and Neshaei, M.A.L., 1996. Beach evolution under random waves, Proc. 25th International Conference on Coastal Engineering, Orlando, Florida, pp. 3006-3018.

Houser, C. and Barrett, G., 2010. Divergent behavior of the swash zone in response to different foreshore slopes and nearshore states. Marine Geology, 271(1-2): 106-118.

Hughes, M.G. and Moseley, A.S., 2007. Hydrokinematic regions within the swash zone. Continental Shelf Research, 27(15): 2000-2013.

Jackson, N.L., Masselink, G. and Nordstrom, K.F., 2004. The role of bore collapse and local shear stresses on the spatial distribution of sediment load in the uprush of an intermediate-state beach. Marine Geology, 203(1-2): 109-118.

Mansard, E.P.D. and Funke, E.R., 1980. The measurement of incident and reflected spectra using a least squares method. Proc. 17th Int. Conf. Coastal Eng., ASCE, New York, p.`pp. 154-172.

Masselink, G., Evans, D., Hughes, M.G. and Russell, P., 2005. Suspended sediment transport in the swash zone of a dissipative beach. Marine Geology, 216(3): 169-189.

Masselink, G. and Hughes, M., 1998. Field investigation of sediment transport in the swash zone. Continental Shelf Research, 18(10): 1179-1199.

Masselink, G. and Puleo, J.A., 2006. Swash-zone morphodynamics. Continental Shelf Research, 26(5): 661-680.

Masselink, G. and Russell, P., 2006. Flow velocities, sediment transport and morphological change in the swash zone of two contrasting beaches. Marine Geology, 227(3-4): 227-240.

Masselink, G., Russell, P., Turner, I. and Blenkinsopp, C., 2009. Net sediment transport and morphological change in the swash zone of a high-energy sandy beach from swash event to tidal cycle time scales. Marine Geology, 267(1-2): 18-35.

Matsunaga, N. and Honji, H., 1980. The backwash vortex. Journal of Fluid Mechanics, 99(4): 813815.

Miles, J., Butt, T. and Russell, P., 2006. Swash zone sediment dynamics: A comparison of a dissipative and an intermediate beach. Marine Geology, 231(1-4): 181-200.

Miles, J.R. and Russell, P.E., 2004. Dynamics of a reflective beach with a low tide terrace. Continental Shelf Research, 24(11): 1219-1247.

Nielsen, P., 2009. Coastal and estuarine processes. Advances series on ocean engineering, 29, 343 pp.

Pritchard, D. and Hogg, A.J., 2005. On the transport of suspended sediment by a swash event on a plane beach. Coastal Engineering, 52(1): 1-23.

Puleo, J.A., Beach, R.A., Holman, R.A. and Allen, J.S., 2000. Swash zone sediment suspension and transport and the importance of bore-generated turbulence. Journal of Geophysical Research, 105(C7): 17021-17044.

Puleo, J.A. and Butt, T., 2006. The first international workshop on swash-zone processes. Continental Shelf Research, 26(5): 556-560.

Puleo, J.A. and Holland, K.T., 2001. Estimating swash zone friction coefficients on a sandy beach. Coastal Engineering, 43(1): 25-40.

Roelvink, D. et al., 2009. Modelling storm impacts on beaches, dunes and barrier islands. Coastal Engineering, 56(11-12): 1133-1152.

Soldati, A. and Marchioli, C., 2009. Physics and modelling of turbulent particle deposition and entrainment: Review of a systematic study. International Journal of Multiphase Flow, 35(9): 827-839.

Turner, I.L., Russell, P.E. and Butt, T., 2008. Measurement of wave-by-wave bed-levels in the swash zone. Coastal Engineering, 55(12): 1237-1242.

Van Dongeren, A.R. and Svendsen, I.A., 1997. An absorbing-generating boundary condition for 
shallow water models Journal of Waterway Port Coastal and Ocean Engineering, 6: 303313.

Van Wellen, E., Baldock, T.E., Chadwick, A.J. and Simmonds, D., 2000. Strand - a model for longshore sediment transport in the swash zone, Proc. 27th International Conference on Coastal Engineering, ASCE, Sydney, pp. 3139-3150.

Watson, G., Barnes, T.C.D. and Peregrine, D.H., 1994. The generation of low frequency waves by a single wave group incident on a beach. Procc. 24th Int. Conf. Coastal Eng., p.`pp. 776-790.

Weir, F.M., Hughes, M.G. and Baldock, T.E., 2006. Beach face and berm morphodynamics fronting a coastal lagoon. Geomorphology, 82(3-4): 331-346. 


\section{List of Captions}

Figure 1.- Instruments layout during SCESE experiments; open squares indicate Acoustic Displacement Sensors (ADS) positions, open circles are Optical Backscatter Sensors (OBS) locations, solid stars are Acoustic Doppler Velocimeters (ADV) and solid squares indicate the position of Pressure sensors transducers (PPT).

Figure 2.- Detail of the manually reshaped shoreface after test 8 of the SCESE experiments. Measured beach profile after test 8 (dash-dotted line) and manually-reshaped beach profile (dotted line).

Figure 3.- Cross-shore distribution of: a) significant wave height and b) beach profile at experimentation time $0,0.45,1.35,2.25,3.15,4.05,5.40$ and 21.15 hours for SANDS experiments.

Figure 4.- Cross-shore distribution of: a) significant wave height and b) beach profile at experimentation $0,0.52,1.03,2.07,3.1,4.13,4.65,5.17$ and 6.2 hours for SCESE experiments.

Figure 5.- Cross-shore distribution of sediment transport computed from bed evolution measurements at the experimentation time interval indicated in the legend and during the SCESE experiments. Reshaping occurred after $4.13 \mathrm{hrs}$.

Figure 6.- a) Water surface power spectrum density before (test 8, solid line) and after (test 10, dotted line) manual reshaping at two different cross-shore location $\mathrm{x}=-61 \mathrm{~m}$ (black) and $\mathrm{x}=-0.46 \mathrm{~m}$ (grey); b) Power spectrum integral energy around frequency band $0.065 \mathrm{~Hz}$ distribution at different test numbers and cross-shore locations indicated in legend during SCESE experiments. Manual reshaping is performed after test 8 . 
Figure 7.- Time distribution of bed level changes computed from the ADSs sensors signal during test 8 at different cross-shore location in the SZ. The solid line indicates the computed bed level while circles indicate time span identified as bed level.

Figure 8.- Time distribution of bed level changes computed from the ADSs sensors signal during test 10 at different cross-shore location in the SZ. The solid line indicates the computed bed level while circles indicate time span identified as bed level.

Figure 9.- Time series of water surface elevation measured at locations $\mathrm{x}=-1.61,-0.38,0.48,1.85$, 3.49, 4.33 and $5.35 \mathrm{~m}$ (from bottom to top), shoreline elevation (left axis) and cross-shore shoreline location (bold black line and right axis) for test 8 (a) and test 10 (b).

Figure 10.- Time series of: a) horizontal velocity measured at location $\mathrm{x}=-0.38 \mathrm{~m}$ for test 8 (green line) and test 10 (blue line); Suspended Sediment Concentration (g/l) measured at locations $\mathrm{x}=$ $0.38,0.61$ and, 1.9 for test 8 (b) and test $10(\mathrm{c})$.

Figure 11.- Time series for measured and ensemble averaged values at $\mathrm{x}=-0.38 \mathrm{~m}$ of water surface elevation (a), horizontal velocity (b), suspended sediment concentration (c) and sediment transport (d). The ensemble average is made for tests before (black) and after (grey) manual reshaping and represented with bold lines.

Table 1. Measured wave conditions during experiments.

Table 2. Equipment distribution along the surf and swash zone during the SCESE experiments, the values in brackets and gray indicate vertical elevation from the bottom; more than one value means 
that different acquisition devices were deployed at the same cross-shore location but at different vertical elevations. 


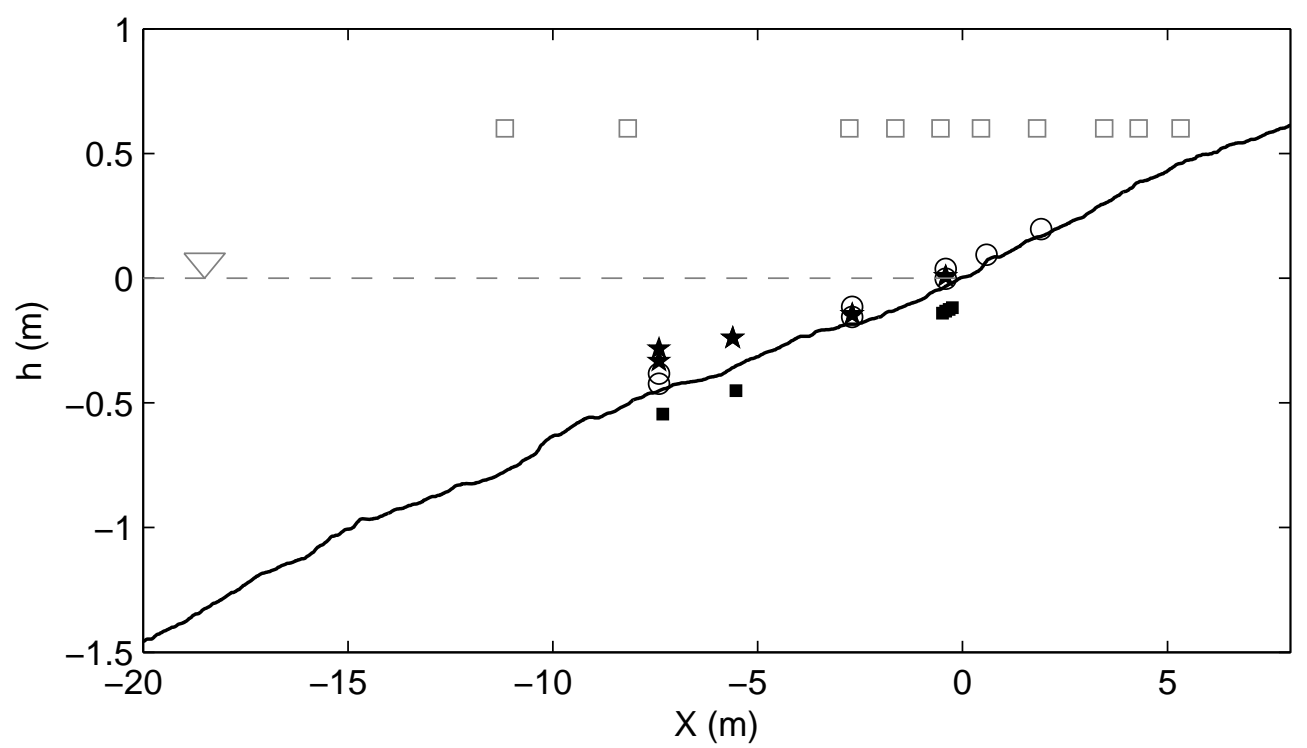

Figure 1.- Instruments layout during SCESE experiments; open squares indicate Acoustic Displacement Sensors (ADS) positions, open circles are Optical Backscatter Sensors (OBS) locations, solid stars are Acoustic Doppler Velocimeters (ADV) and solid squares indicate the position of Pressure sensors transducers (PPT).

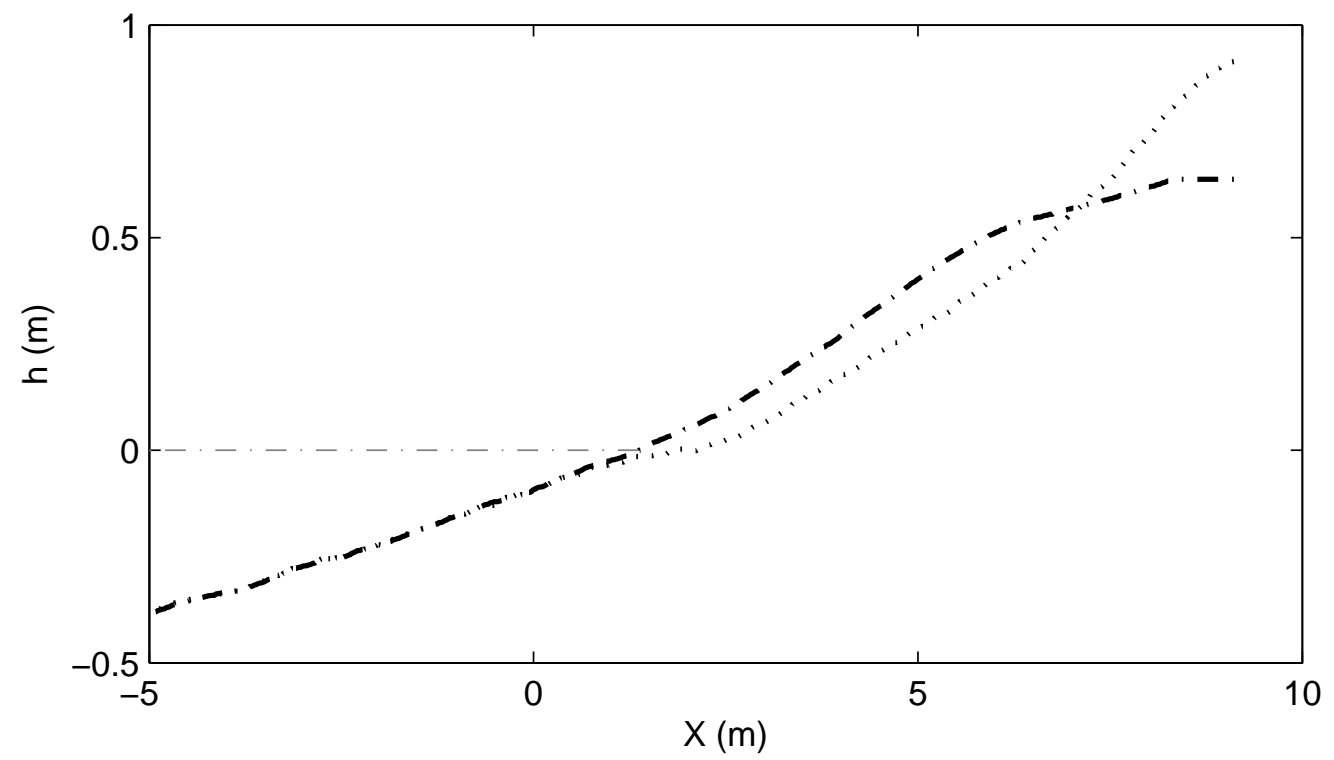

Figure 2.- Detail of the manually reshaped shoreface after test 8 of the SCESE experiments. Measured beach profile after test 8 (dash-dotted line) and manually-reshaped beach profile (dotted line). 

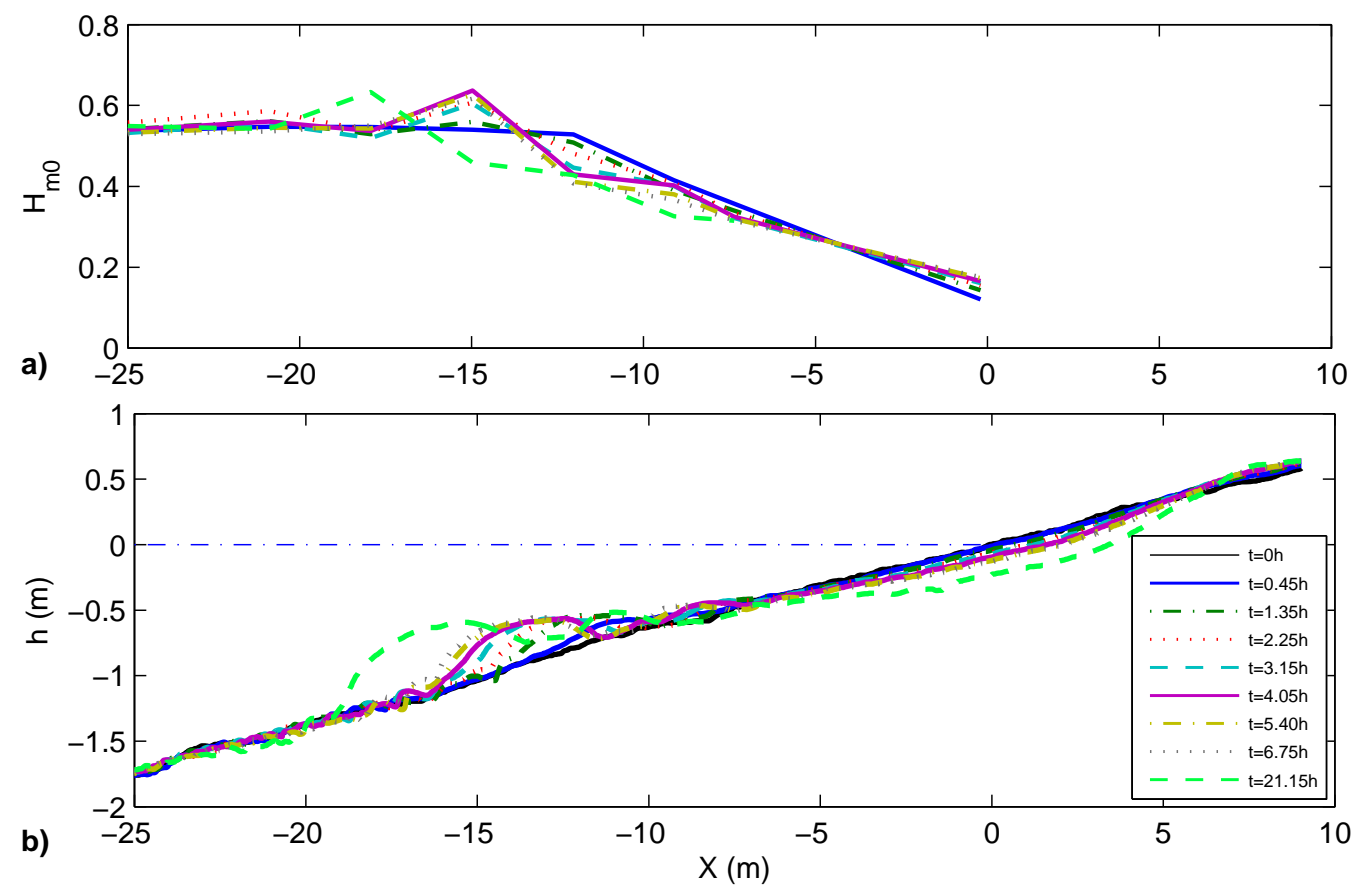

Figure 3.- Cross-shore distribution of: a) significant wave height and b) beach profile at experimentation time $0,0.45,1.35,2.25,3.15,4.05,5.40$ and 21.15 hours for SANDS experiments.

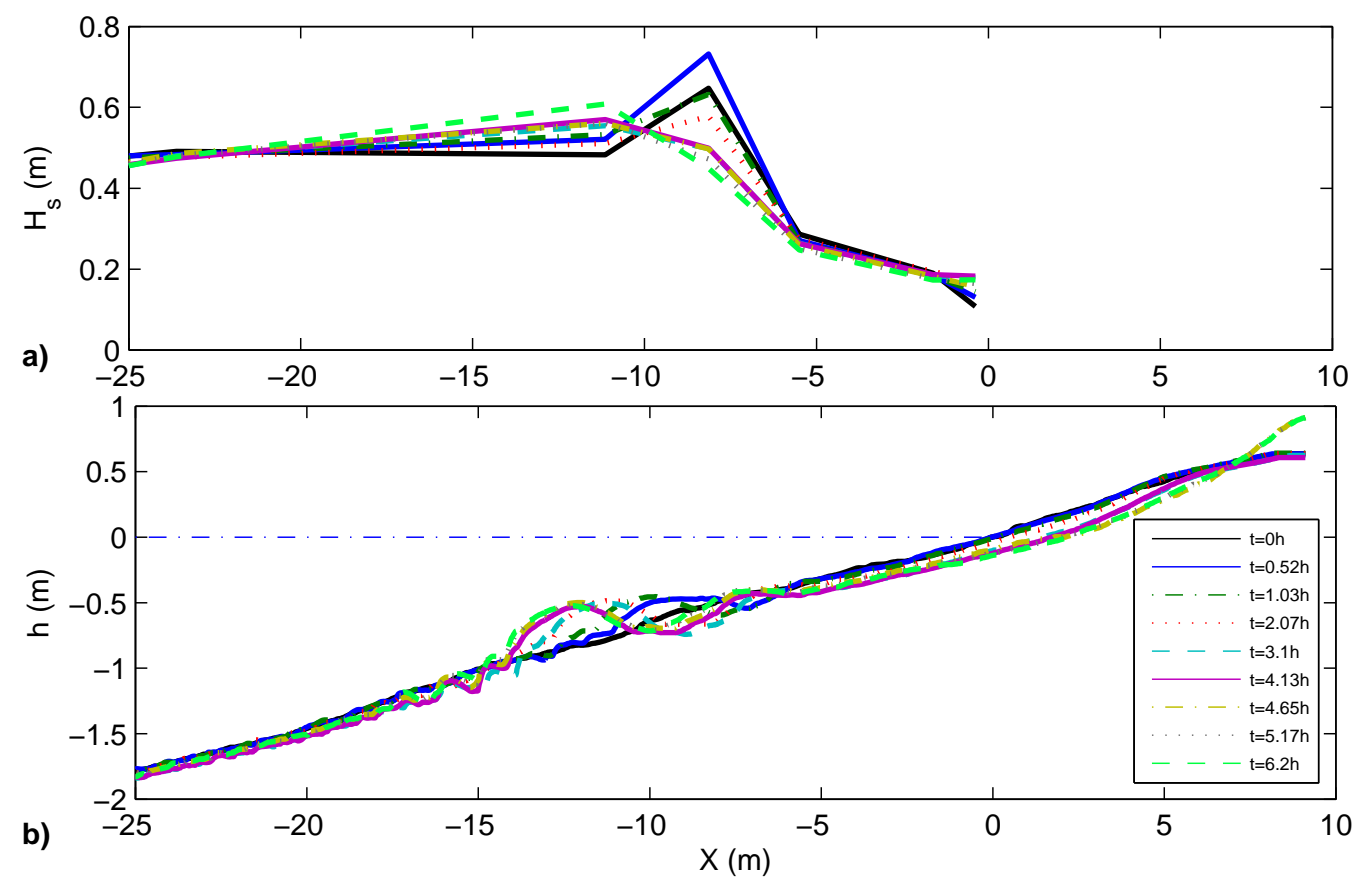

Figure 4.- Cross-shore distribution of: a) significant wave height and b) beach profile at experimentation $0,0.52,1.03,2.07,3.1,4.13,4.65,5.17$ and 6.2 hours for SCESE experiments. 


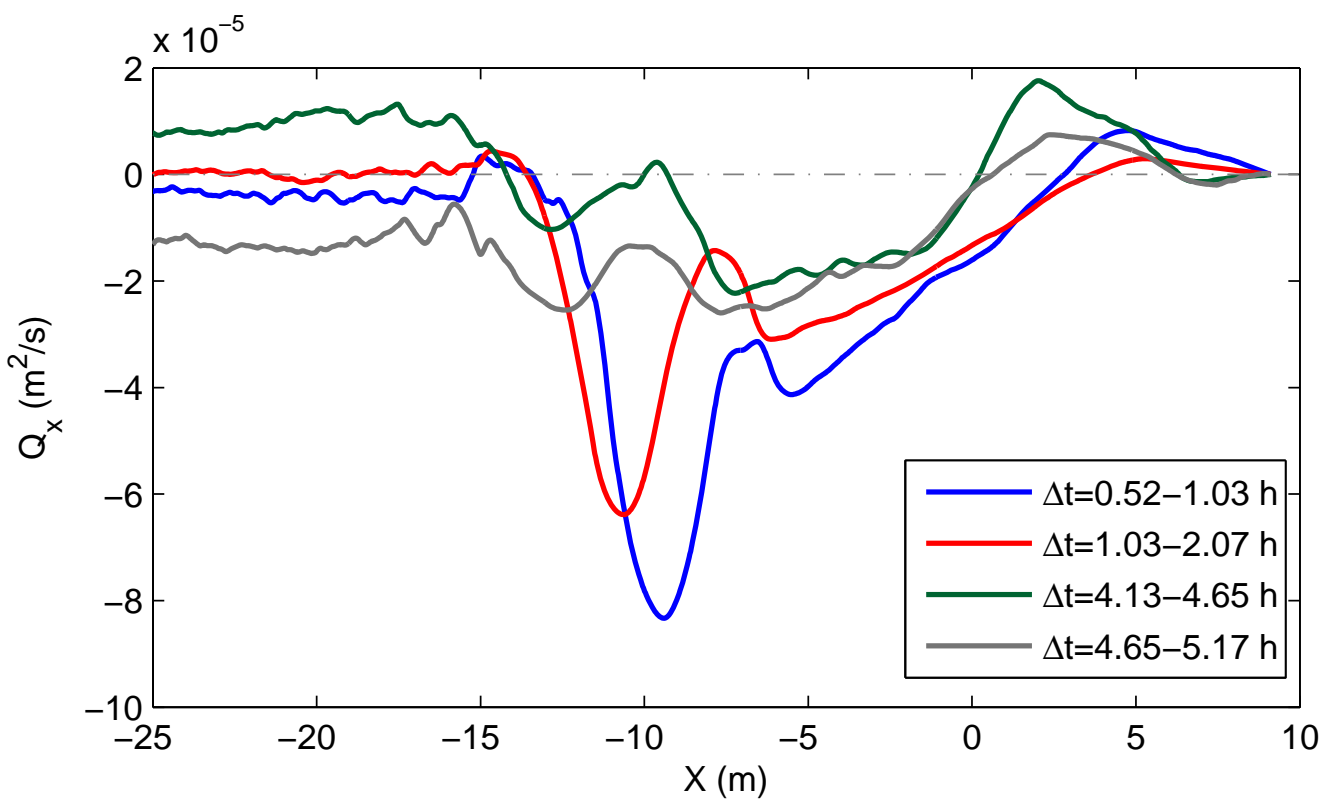

Figure 5.- Cross-shore distribution of sediment transport computed from bed evolution measurements at the experimentation time interval indicated in the legend and during the SCESE experiments. Reshaping occurred after $4.13 \mathrm{hrs}$. 


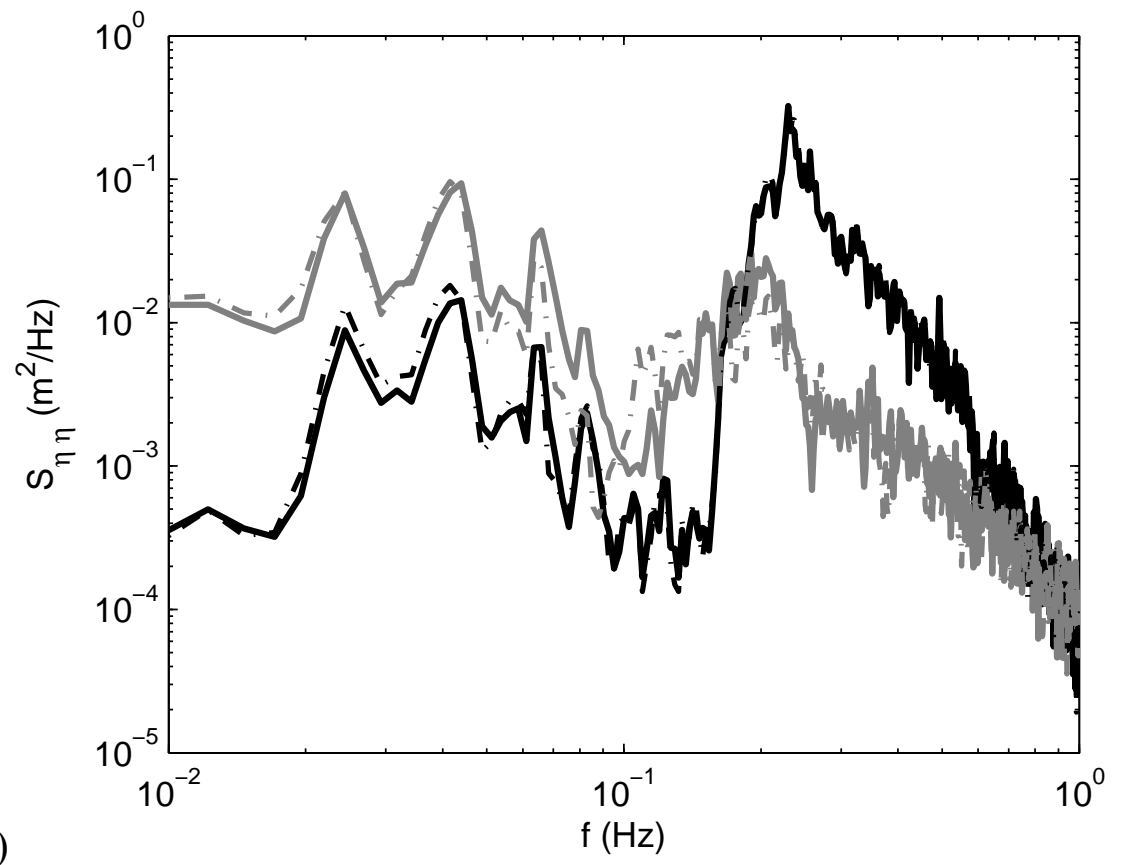

a)

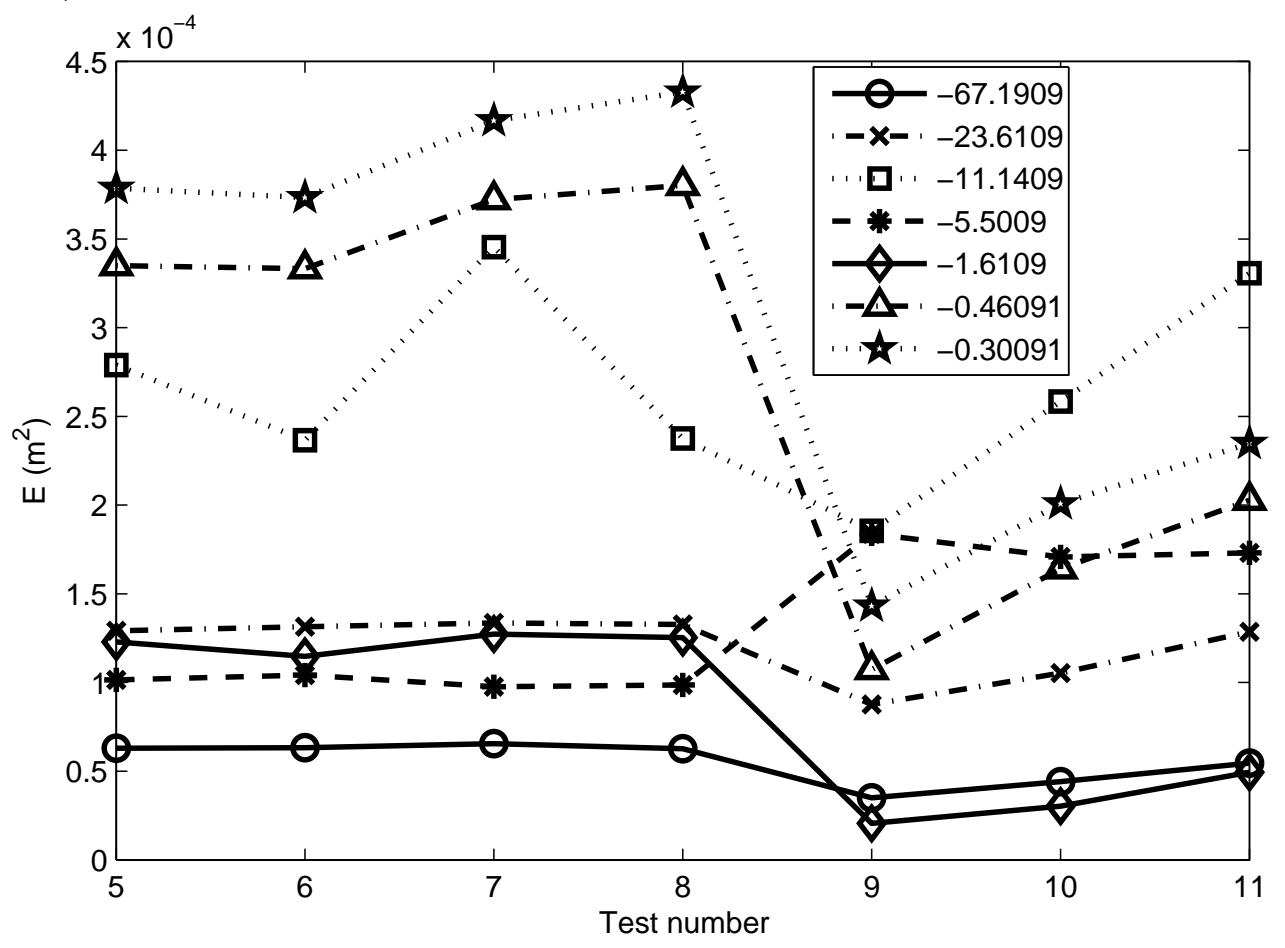

b)

Figure 6.- a) Water surface power spectrum density before (test 8 , solid line) and after (test 10 , dotted line) manual reshaping at two different cross-shore location $\mathrm{x}=-61 \mathrm{~m}$ (black) and $\mathrm{x}=-0.46 \mathrm{~m}$ (grey); b) Power spectrum integral energy around frequency band $0.065 \mathrm{~Hz}$ distribution at different test numbers and cross-shore locations indicated in legend during SCESE experiments. Manual reshaping is performed after test 8 . 

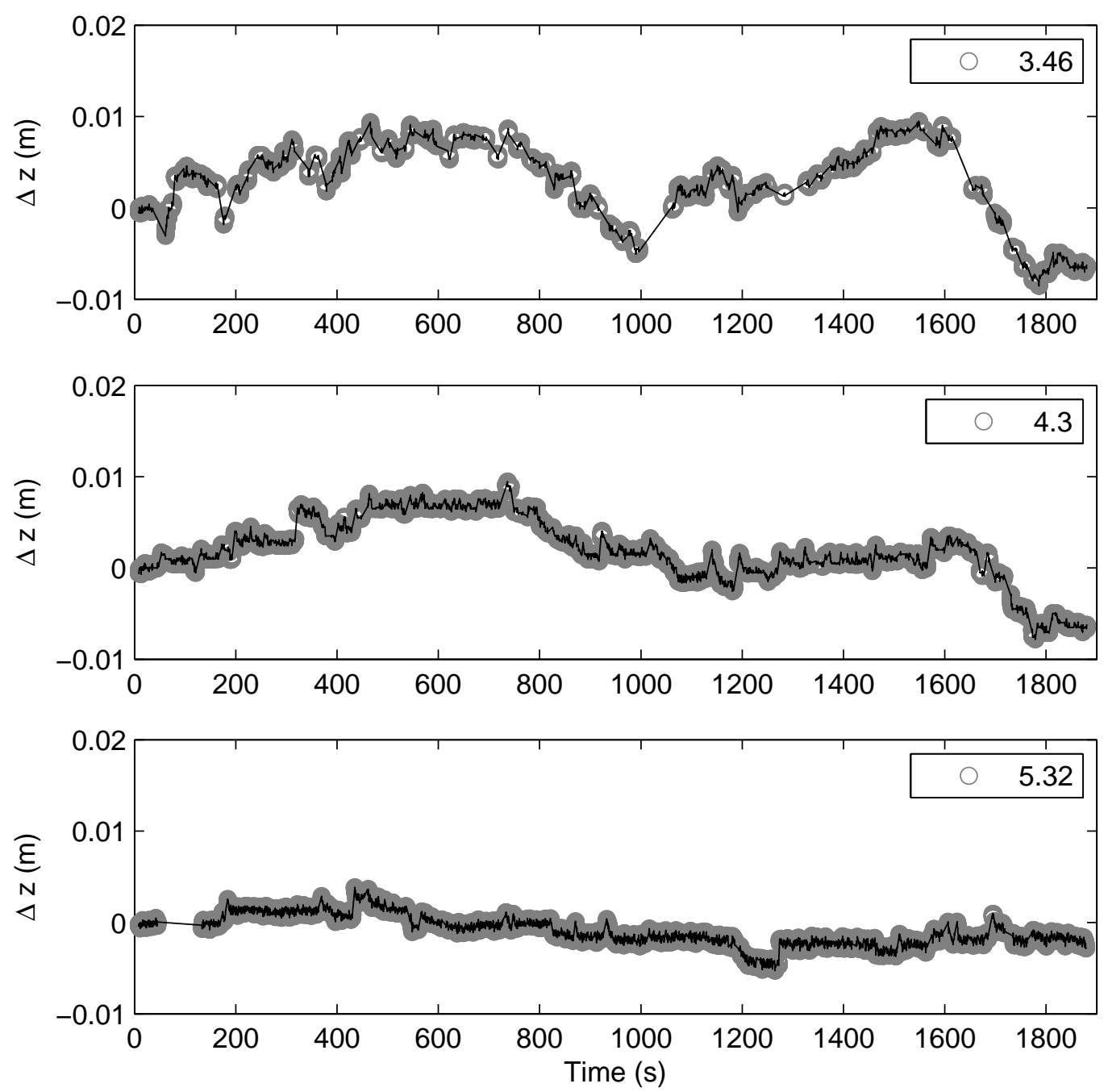

Figure 7.- Time distribution of bed level changes computed from the ADSs sensors signal during test 8 at different cross-shore location in the SZ. The solid line indicates the computed bed level while circles indicate time span identified as bed level. 

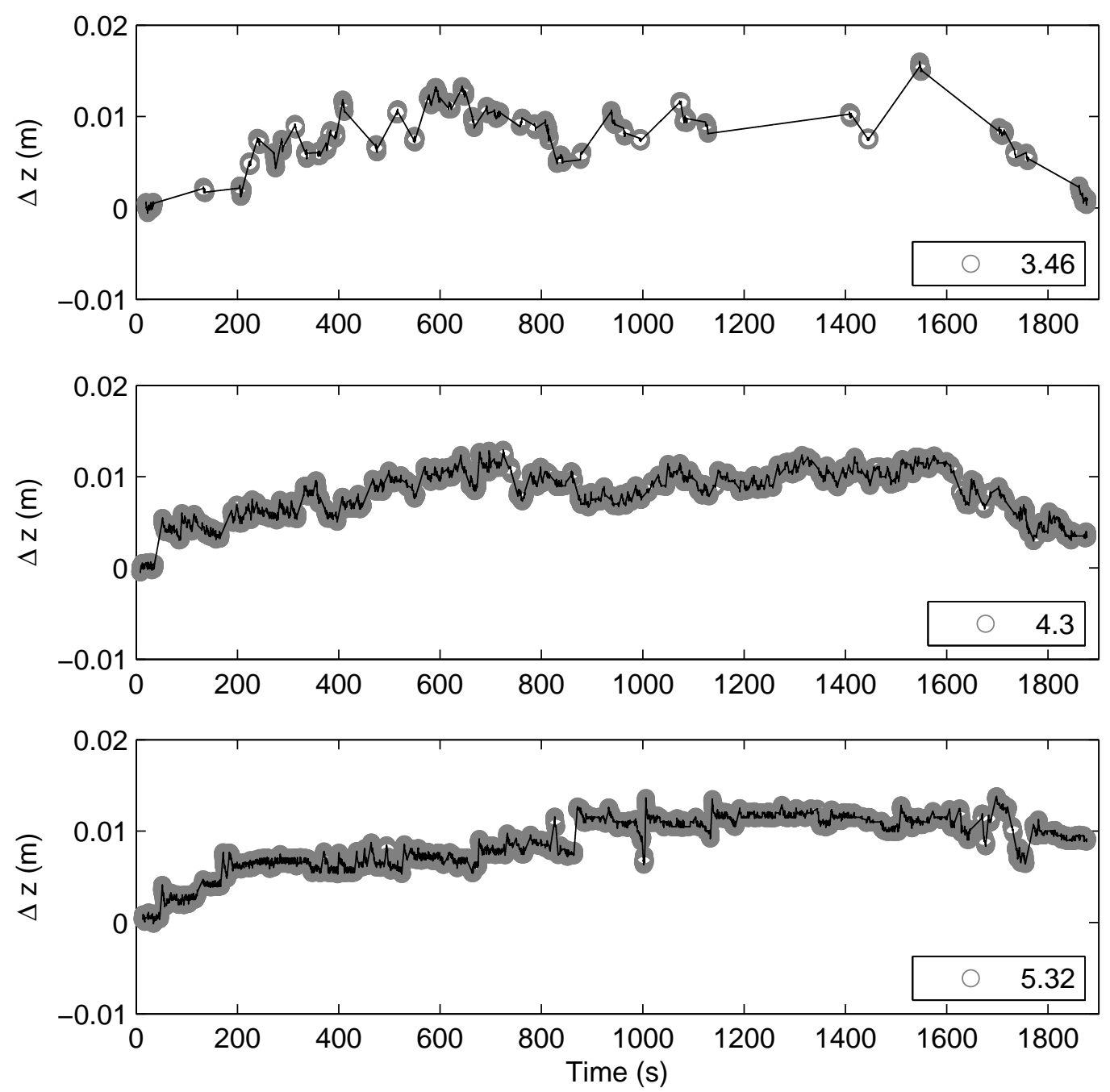

Figure 8.- Time distribution of bed level changes computed from the ADSs sensors signal during test 10 at different cross-shore location in the SZ. The solid line indicates the computed bed level while circles indicate time span identified as bed level. 


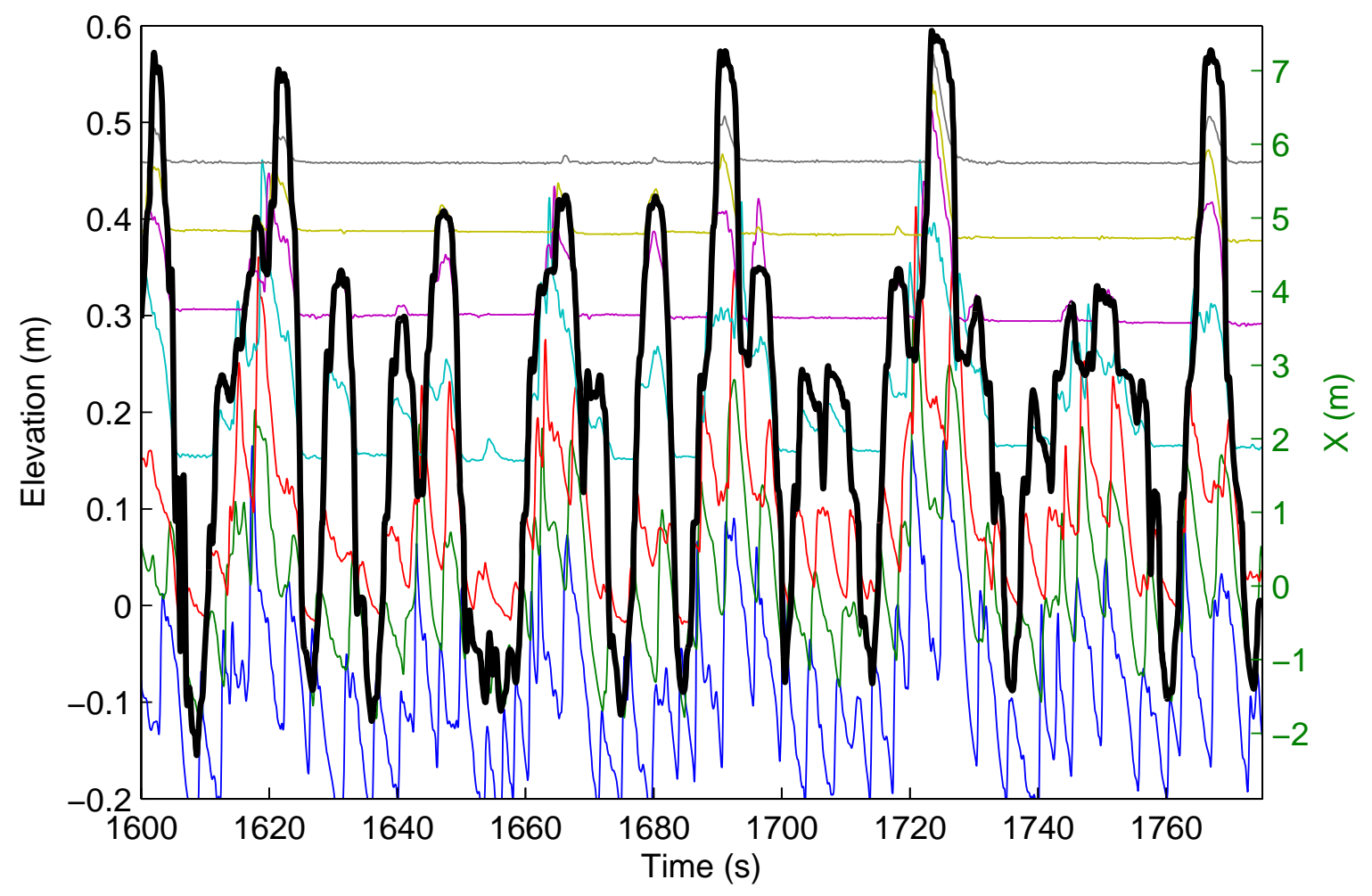

a)

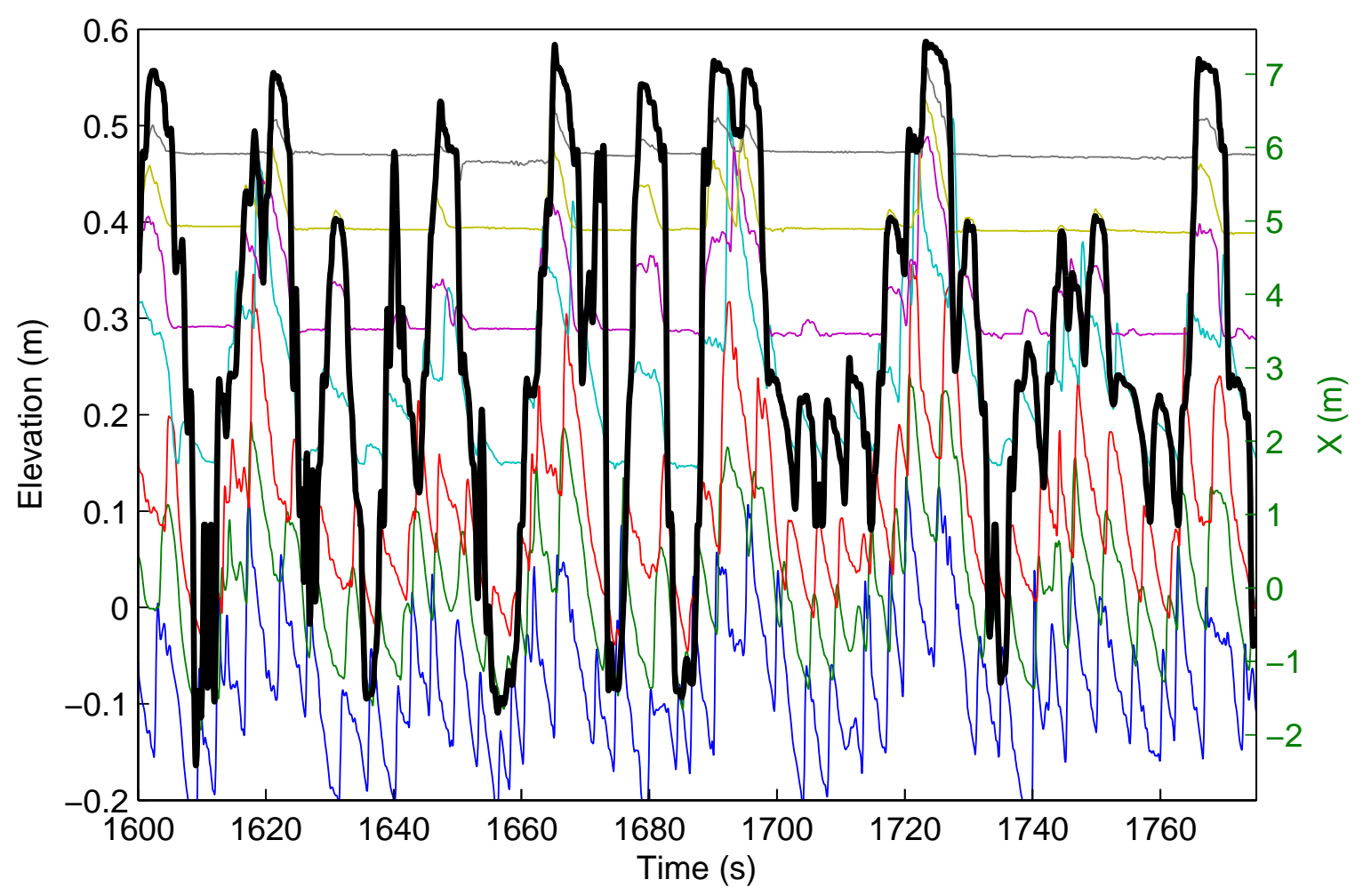

b)

Figure 9.- Time series of water surface elevation measured at locations $\mathrm{x}=-1.61,-0.38,0.48,1.85$, $3.49,4.33$ and $5.35 \mathrm{~m}$ (from bottom to top), shoreline elevation (left axis) and cross-shore shoreline location (bold black line and right axis) for test 8 (a) and test 10 (b). 

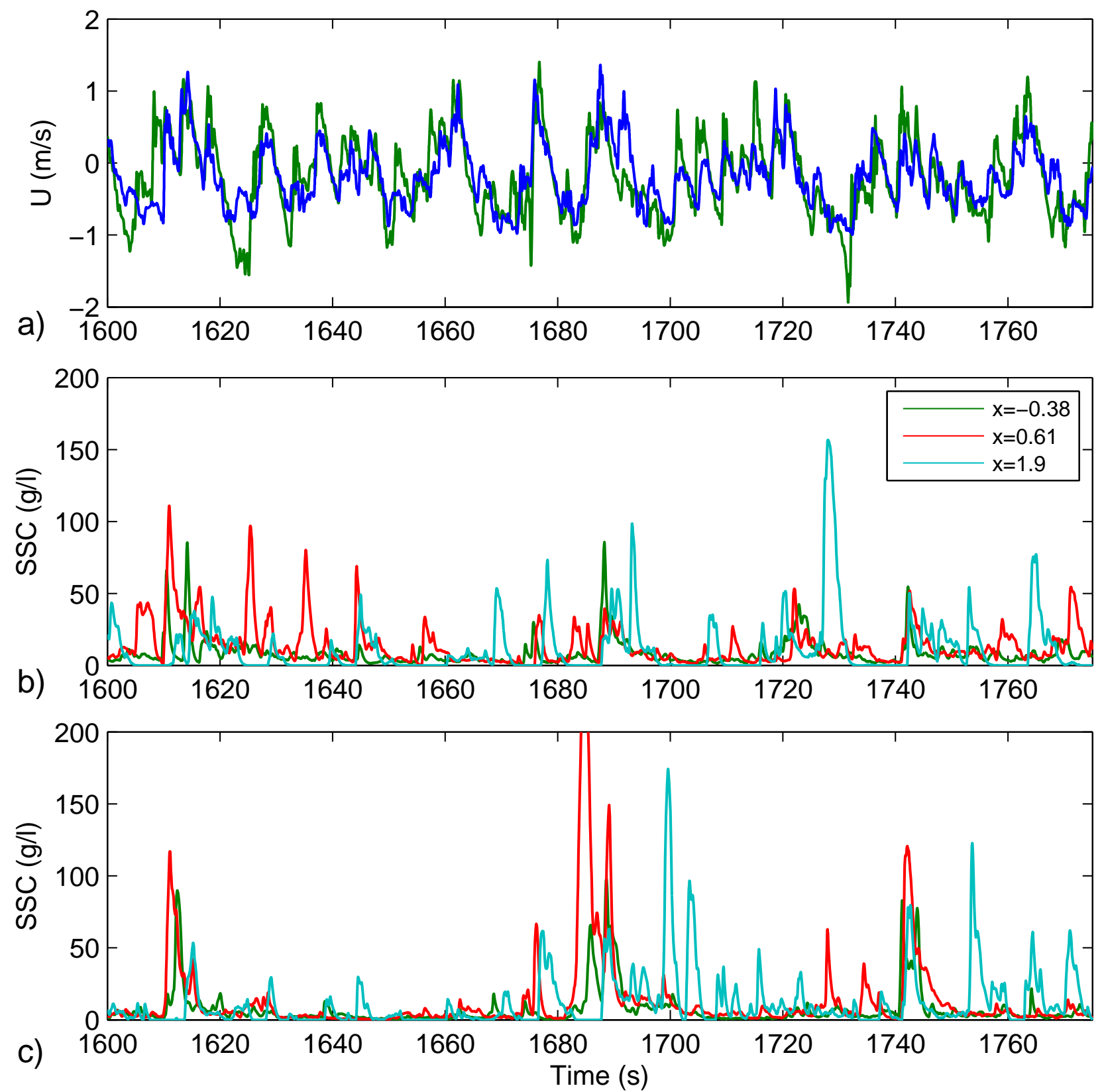

Figure 10.- Time series of: a) horizontal velocity measured at location $\mathrm{x}=-0.38 \mathrm{~m}$ for test 8 (green line) and test 10 (blue line); Suspended Sediment Concentration $(\mathrm{g} / \mathrm{l})$ measured at locations $\mathrm{x}=$ $0.38,0.61$ and, $1.9 \mathrm{~m}$ for test 8 (b) and test $10(\mathrm{c})$. 


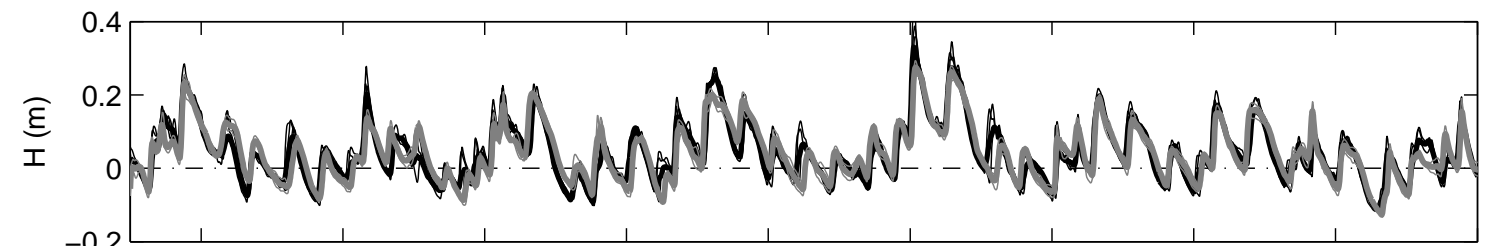

a)

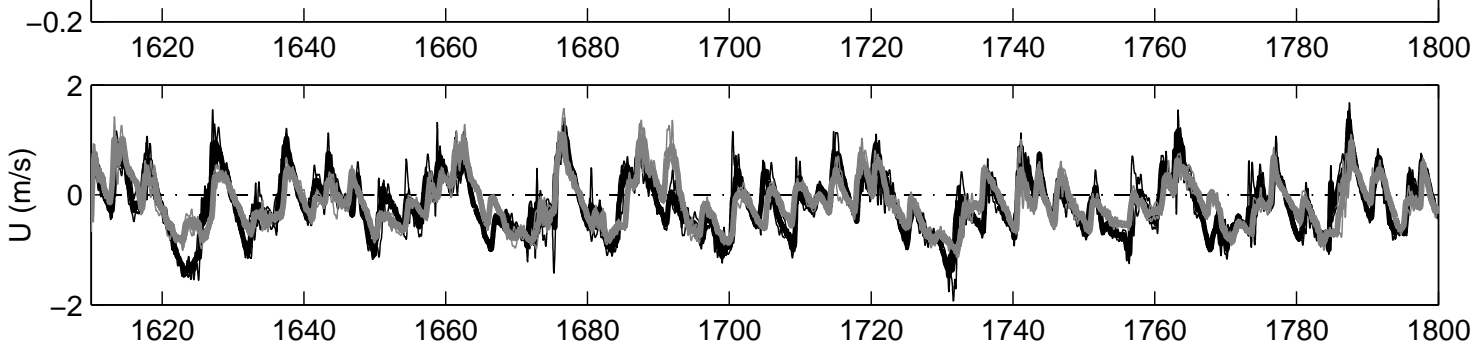

b)

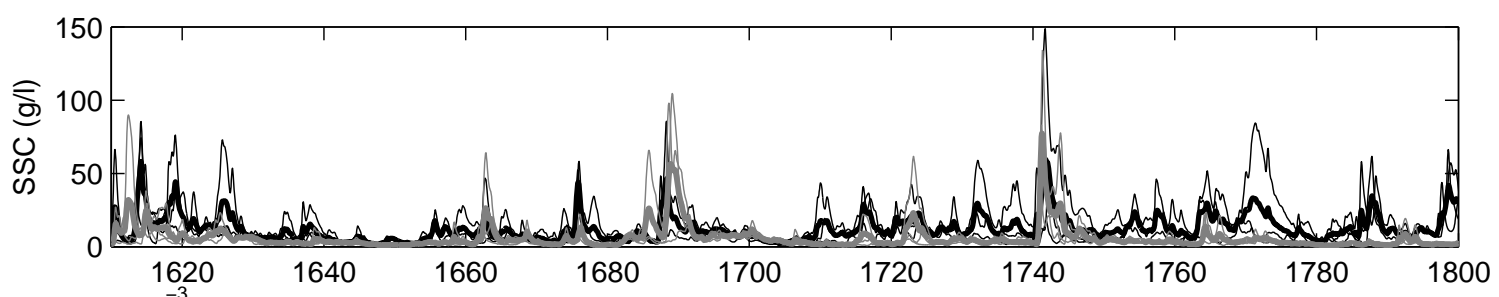

c)

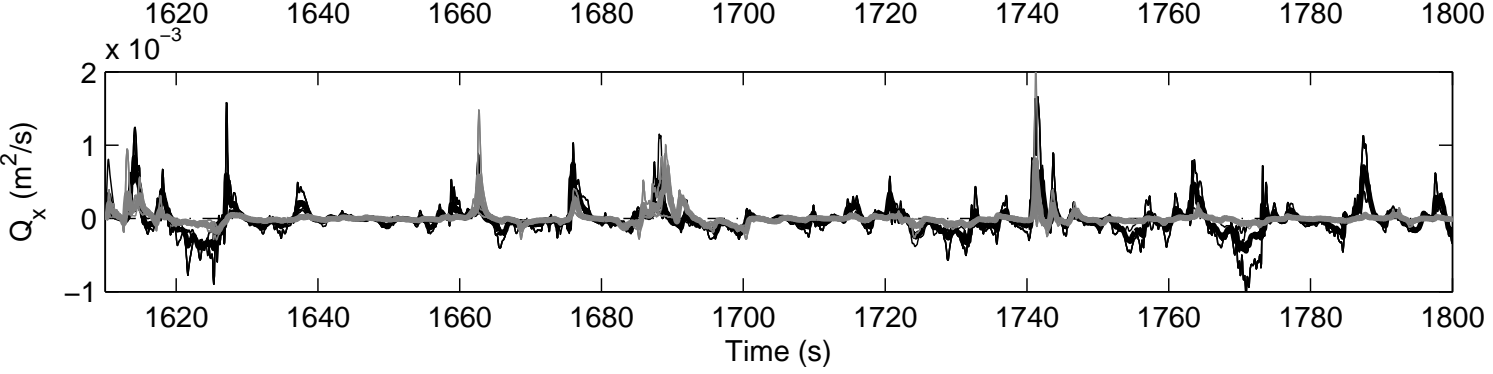

Figure 11.- Time series for measured and ensemble averaged values at $\mathrm{x}=-0.38 \mathrm{~m}$ of water surface elevation (a), horizontal velocity (b), suspended sediment concentration (c) and sediment transport (d). The ensemble average is made for tests before (black) and after (grey) manual reshaping and represented with bold lines. 